\title{
Subannual to Interannual Variabilities of SST in the North Atlantic Ocean
}

\author{
XIAOFAN LI \\ Key Laboratory of Geoscience Big Data and Deep Resource of Zhejiang Province, School of Earth Sciences, Zhejiang \\ University, Hangzhou, Zhejiang, China \\ ZENG-ZHEN HU \\ Climate Prediction Center, NOAA/NWS/NCEP, College Park, Maryland \\ BOHUA HUANG \\ Center for Ocean-Land-Atmosphere Studies, and Department of Atmospheric, Oceanic, and Earth Sciences, College of \\ Science, George Mason University, Fairfax, Virginia
}

(Manuscript received 23 July 2019, in final form 26 March 2020)

\begin{abstract}
Based on observational data, this work examines the multi-time-scale feature of the sea surface temperature (SST) variability averaged in the whole North Atlantic Ocean (to be referred to as NASST), as well as its time-scale-dependent connections with El Niño-Southern Oscillation (ENSO) and the North Atlantic Oscillation (NAO). Traditionally, the NASST index is used to characterize the SST trend and multidecadal variability in the North Atlantic. This study found that superimposed on a prominent long-term trend, NASST is nonnegligible at subannual and interannual time scales, compared with that at decadal to multidecadal time scales. Spatially, the interannual variation of NASST is characterized by a horseshoe-like pattern of the SST anomaly (SSTA) in the North Atlantic. It is mainly a lagged response to ENSO through the atmospheric bridge, and NAO plays a secondary role. At the subannual time scale, both ENSO and NAO play a role in generating the fluctuations of NASST and a horseshoe-like pattern in the North Atlantic. Nevertheless, both the ENSO- and NAO-driven variations only explain a small fraction of the variances in both the interannual and subannual time scales. Thus, other factors unrelated to ENSO or NAO may play a more important role. The associated thermodynamical processes are similar at the two time scales; however, the dynamical processes have a significant contribution to the subannual component, but not to the interannual component. Thus, the SSTA averaged in the North Atlantic as a whole varies at different time scales and is associated with different mechanisms.
\end{abstract}

\section{Introduction}

Multidecadal variation of sea surface temperature (SST) in the North Atlantic is substantial with a dominant time scale of $60-80$ years (Fig. 1a) and was thus named originally as the Atlantic multidecadal oscillation (AMO; Schlesinger 1994; Kerr 2000). Recently, it is also referred to as the Atlantic multidecadal variability (AMV; Ting et al. 2011) to reflect its broad frequency range of fluctuations on the multidecadal time scale. Spatially, the AMV is characterized as the SST anomalies (SSTAs) of the same sign over the whole Atlantic, with larger anomalies extending from the Newfoundland

Corresponding author: Xiaofan Li, xiaofanli@zju.edu to the eastern Atlantic in the extratropics and then turning to the subtropics (e.g., see Fig. 1b of Sutton and Hodson 2005).

As a key player for the multidecadal variations of climate, the AMO affects the multidecadal variations of European and North American climate (Schlesinger 1994; Enfield et al. 2001; Sutton and Hodson 2005; Zhang and Delworth 2006; Trenberth and Shea 2006; Chylek and Lesins 2008; Ting et al. 2009; Huang et al. 2015; Monerie et al. 2019). For example, a warm phase of the AMO may lead to an increase of summer drought frequency and warmer temperatures in the United States, and an increase of summer precipitation and temperatures in western Europe (Sutton and Hodson 2005). Also, the AMO modulates hurricane activity by 


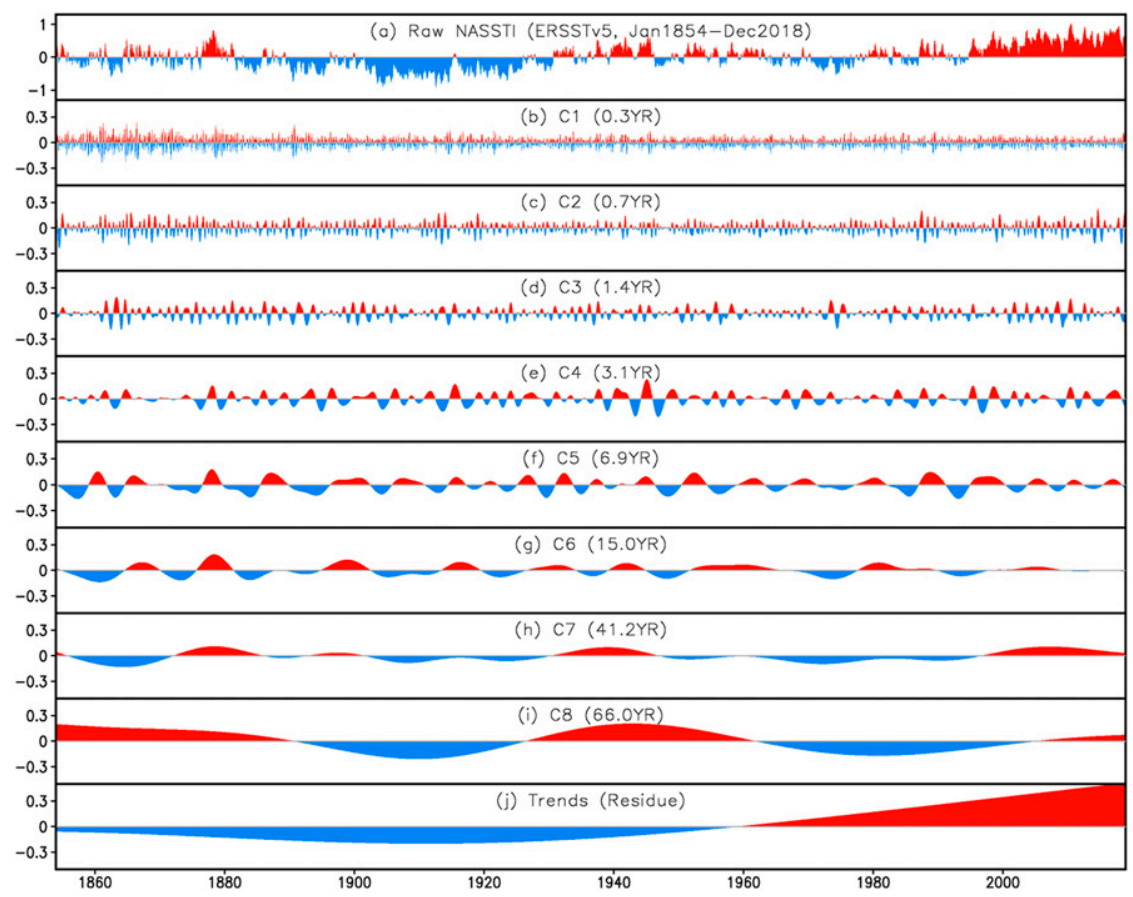

FIG. 1. (a) Monthly mean NASSTI in January 1854-December 2018, which is defined as the ERSSTv5 SSTAs averaged in the North Atlantic $\left(0^{\circ}-60^{\circ} \mathrm{N}, 80^{\circ} \mathrm{W}-0^{\circ}\right)$ and $(\mathrm{b})-(\mathrm{j})$ the EEMD components. The number in the parentheses in (b)-(i) represents the averaged period of the component. Unit is ${ }^{\circ} \mathrm{C}$.

affecting the SST variability in the main development region of Atlantic hurricane (e.g., Chylek and Lesins 2008; Ting et al. 2009).

Due to its significance on the climate variations over the North Atlantic and the surrounding regions, there have been extensive studies about the variability of the AMO and its profound impact (Zhang and Delworth 2007; Guan and Nigam 2009; Sun et al. 2015; Lübbecke et al. 2018). However, there is still controversy about the mechanisms of AMO formation (Gulev et al. 2013; Zhang and Wang 2013; Clement et al. 2015; O'Reilly et al. 2016; Zhang et al. 2016; Cane et al. 2017; Srivastava and DelSole 2017; Garuba et al. 2018). For example, in addition to observational evidence (McCarthy et al. 2015), Wang and Zhang (2013) argued that AMO-like variability in climate models seems associated with the variations in the North Atlantic branch of the overturning circulation. Garuba et al. (2018) noted that the AMV is largely driven by ocean circulation variability, but its power is modulated by the strength of atmosphereocean coupling. Nevertheless, some models and observation evidence suggested that at least the tropical portion of the AMO is mainly driven by variations of atmospheric circulation due to changes in clouds, atmospheric dust, and surface heat flux (Yuan et al. 2016; Brown et al. 2016).
In fact, in addition to the multidecadal variability (Deser and Blackmon 1993; McCarthy et al. 2018; Nigam et al. 2018), SSTA in the North Atlantic as contained in the AMO index also varies at other time scales, including long-term trend (such as the strong warming tendency since the 1970s), interannual variations and higher-frequency (interseasonal and seasonal time scales) fluctuations (Fig. 1). It is anticipated that variabilities of the AMO at different time scales may be associated with different mechanisms and have different connections with various modes of climate variability, such as El Niño-Southern Oscillation (ENSO) and North Atlantic Oscillation (NAO).

In this work, we examined the multi-time-scale feature of SST variability averaged in the North Atlantic as a whole using observational (analysis and reanalysis) datasets. Some previous works have studied the variability of the North Atlantic as a whole but they mostly focused on multidecadal and subdecadal time scales (Álvarez-García et al. 2008, 2011; Frankcombe et al. 2010; Reintges et al. 2017; Martin et al. 2019). In fact, as seen from the raw North Atlantic SST (NASST) index (NASSTI; Fig. 1a) and the ensemble empirical mode decomposition (EEMD results (Figs. 1b-i), there are some higher-frequency variations superimposed on the multidecadal variations and long-term trend. For the interannual and subannual time-scale variations in the 
North Atlantic, previous studies have focused on their spatial patterns and associations with ENSO and NAO (e.g., Seager et al. 2000; Czaja and Marshall 2001; Hu and Huang 2006; Hu et al. 2011). For the North Atlantic as a whole, these higher-frequency variations are seldom examined, which is the focus of this work. In this study, after decomposing SSTA averaged in the whole North Atlantic into different time scales, their time-scaledependent connections with the ENSO and NAO, as well as the associated mechanisms are examined. The rest of the paper is organized as follows: The data and methods used in this work are introduced in section 2; the multi-time-scale feature is shown in section 3; the mechanisms are examined in section 4 ; and a summary is given in section 5 .

\section{Data and methods}

The monthly mean of SST on a $2^{\circ} \times 2^{\circ}$ grid in January 1854-December 2018 is from ERSST version 5 (ERSSTv5; Huang et al. 2017). To measure SST variability in the North Atlantic, NASSTI is adopted here, which is defined as the monthly SSTAs averaged in the North Atlantic $\left(0^{\circ}\right.$ $60^{\circ} \mathrm{N}, 80^{\circ} \mathrm{W}-0^{\circ}$ ), following Trenberth and Shea (2006), but we did not subtract the global mean SSTA. The analysis of Trenberth and Shea (2006) focused on the multidecadal time scale by using the annual mean and a low-pass filter and by subtracting global SSTAs from $60^{\circ} \mathrm{S}$ to $60^{\circ} \mathrm{N}$. For analyzing the connections between the NASST and ENSO, the monthly mean Niño-3.4 index is used to represent ENSO. The Niño-3.4 index is defined as the SSTA averaged in $\left(5^{\circ} \mathrm{S}-5^{\circ} \mathrm{N}, 120^{\circ}-170^{\circ} \mathrm{W}\right)$ and calculated using the ERSSTv5 SST (see Fig. 5b).

Accompanying the SST analysis, we have diagnosed the heat budget in ocean mixed layer (OML) using the monthly mean output of the Global Ocean Data Assimilation System (GODAS; Behringer 2007; Huang et al. 2010; Hu et al. 2016) forced by the surface wind stress data, as well as the surface heat and freshwater flux data, from the NCEP-DOE reanalysis (R2; Kanamitsu et al. 2002). The GODAS data are on a $1^{\circ} \times 1^{\circ}$ grid in January 1979-December 2018. The tendency of ocean temperature of OML is defined as

$$
\frac{\partial T}{\partial t}=Q_{u}+Q_{v}+Q_{w}+Q_{z z}+Q_{q}+R,
$$

where $\partial T / \partial t$ is the temperature tendency of OML; $Q_{u}$ and $Q_{v}$ are zonal and meridional advection, respectively; and $Q_{w}\left(Q_{z z}\right)$ is vertical entrainment (diffusion); $Q_{q}$ is the adjusted surface heat flux, which is the prescribed net surface heat flux plus a heat flux correction term minus the penetrative shortwave radiation; and $R$ is the residual term and contains the effect of horizontal heat diffusion and the contributions of the submonthly processes, which is smaller compared with the other terms in the tropical Pacific (Huang et al. 2010). In the North Atlantic, the heat budget closure is also reasonable (not shown). A density difference of $0.125 \mathrm{~kg} \mathrm{~m}^{-3}$ between the ocean surface and the bottom of OML was used as the criterion to determine the depth of OML. In GODAS, the ocean model (MOM3) integration is mainly forced by the prescribed surface fluxes from R2. However, to prevent a model drift from the observed SST under the noninteractive R2 surface heat flux forcing, an additional heat flux term is added to nudge the model SST at every time step of integration toward the observed SST with a restoring time scale of 5 days (Huang et al. 2010). Therefore, this interactive nudging term based on the observed SST can be considered as a GODAS surface heat flux correction to the prescribed R2 surface heat flux, which is a part of the total nonpenetrative surface heat flux received by the model and plays the role of sustaining the GODAS SST close to the observed SST. Details about the calculations can be found in Huang et al. (2010).

An NAO index (NAOI) based on the procedure of Barnston and Livezey (1987) is used in this study. First, monthly varied NAO patterns are identified based on rotated principal component analysis of monthly mean standardized geopotential height at $500 \mathrm{hPa}$ (H500) anomalies from the NCEP-NCAR reanalysis on a $2.5^{\circ} \times 2.5^{\circ}$ grid in $20^{\circ}-90^{\circ} \mathrm{N}$ (Kalnay et al. 1996). Then the NAOI in January 1950-December 2018 is calculated through the projection of the monthly mean H500 anomalies onto the corresponding NAO pattern in the month (Fig. 10b). The NAOI data are updated every month at the Climate Prediction Center (CPC) and are downloaded from the CPC web page (http://www.cpc.ncep. noaa.gov/products/precip/CWlink/pna/norm.nao.monthly. b5001.current.ascii). H500 and surface wind from the NCEP-NCAR reanalysis (Kalnay et al. 1996) and the latent heat flux in January 1958-December 2016 from the OAFlux (Yu and Weller 2007) are also analyzed.

The method of EEMD is adopted to identify the multi-time-scale variability of NASST (Huang and Wu 2008; Wu and Huang 2009; Huang et al. 2012). Unlike Fourier transform-based time series analysis using a priori "global" basis functions of rigid periods, EEMD is adaptive and derives optimal frequencies from the data itself and provides a natural filter to separate temporally orthogonal components of different time scales. We first decompose NASSTI into time-frequency modes and then combine the corresponding modes in certain frequency bands into subannual and interannual components of the NASSTI based on the EEMD decompositions. Here, the period of each mode is estimated by the mean of time lapse between two extrema in the mode. Using these 
NASSTI components, we further examine their lead-lag correlations with ENSO/NAO, heat flux, atmospheric circulation, and large-scale SSTAs, as well as the heat budget of the OML. Through these analyses, we can demonstrate the multi-time-scale variability feature of SSTA in the North Atlantic as a whole and reveal various physical processes associated with these variabilities.

In this work, all anomalies, including SST and all other variables, refer to their corresponding monthly climatologies in January 1981-December 2010. Correlations are tested using the Student's $t$ test at the $95 \%$ significance level with independent sample size estimations following Bretherton et al. (1999).

\section{Multi-time-scale variability}

From EEMD analysis, it is seen that in addition to the profound warming trend, NASSTI varies from subannual to multidecadal time scales (Fig. 1). Figure 2 shows the standard deviations (STDV) of the raw NASSTI and each of the EEMD components. The largest STDV is from the trend. The second-largest STDV is at a multidecadal time scale around 66 years and it is referred to as the AMO time scale (Schlesinger 1994; Kerr 2000; Enfield et al. 2001). The amplitudes of STDVs are comparable for all the other time scales from 0.3 to 41.2 years. The time scales of 15.0 and 41.2 years are generally consistent with a broad peak at $10-30-y r$ period in North Atlantic SSTA noted previously (Czaja and Marshall 2001; Frankcombe et al. 2010; Nigam et al. 2018; references therein). Thus, in addition to the AMO time-scale variability and warming trend (Figs. 1i,j and 2 ), the SST variation in the North Atlantic also fluctuates at subannual, interannual, decadal, and interdecadal time scales (Figs. 1b-h and 2). Moreover, these different time-scale components of NASSTI are associated with various spatial patterns of SSTA, which are examined next.

For the spatial connection, the AMO time-scale variation of NASSTI is associated with same-sign SSTA variations in the North Atlantic, and the opposite variation between the North Pacific and east/central tropical Pacific (Fig. 3i). The interdecadal component at a time scale around 41.2 years is associated with same-sign SSTA variations in all the ocean basins (Fig. 3h), which is similar to the corresponding correlations with the total NASSTI (Fig. 3a). For the component of NASSTI with time scales around 15.0 years (Fig. 3g), the correlation pattern in the North Atlantic is a horseshoe-like pattern. Due to the short lengths of the datasets used in this work, these decadal to multidecadal (C6, C7, and C8) components will not be further discussed in the following analysis.

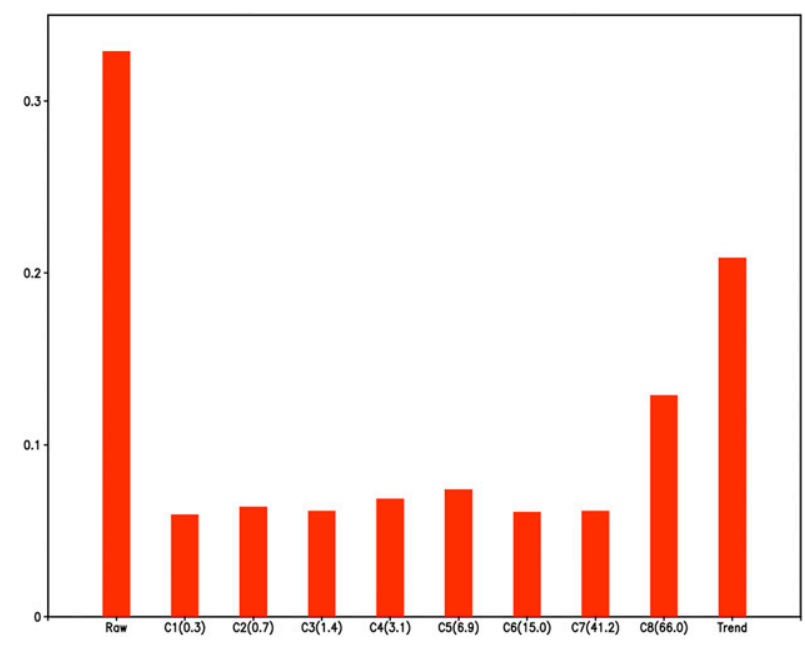

FIG. 2. Standard deviations of monthly mean of NASSTI $\left({ }^{\circ} \mathrm{C}\right)$ and the EEMD components $\left({ }^{\circ} \mathrm{C}\right)$. The numbers in the parentheses below the $x$ axis represent the averaged periods of the EEMD components.

For the components of NASSTI with time scales around 3.1 and 6.9 years (Figs. 3e,f), their correlation patterns are similar and a horseshoe-like pattern is present in the North Atlantic. The horseshoe SSTA pattern during summer has been demonstrated by previous studies to drive NAO in the coming winter (Czaja and Frankignoul 1999, 2002). On the other hand, the winter NAO-driven SSTA pattern is a tripole pattern (Cayan 1992; Marshall et al. 2001; Czaja and Frankignoul 2002; Deser et al. 2010; Hurrell and Deser 2010). Nevertheless, the horseshoe and tripole pattern have spatially overlapped, especially in the tropical Atlantic. It has been suggested that the horseshoe/tripole-like pattern is statistically associated with NAO and ENSO (Hurrell 1995; Czaja and Frankignoul 2002; Hurrell et al. 2003; Visbeck et al. 2003; Hu and Huang 2006; Hu et al. 2011; Li et al. 2013). Also, significant correlations are present in the tropical Pacific, which may imply an association of these two components of NASSTI with ENSO (e.g., Enfield and Mayer 1997; Dommenget et al. 2006; Hu and Huang 2007; Hu et al. 2011; Ham et al. 2013; Lübbecke et al. 2018). Based on the similarities of the correlations with SSTA in the North Atlantic and tropical Pacific Oceans, we add these two components together as interannual variations (Fig. 4a). The associated physical processes will be examined in section 4a.

The correlations of SSTA with NASSTI at time scales around $0.3,0.7$, and 1.4 years also show a similar spatial pattern (Figs. 3b-d). The horseshoe-like significant correlations are confined to the North Atlantic. Meanwhile, there are no significant correlations outside the North Atlantic (Figs. 3b-d), implying that the 


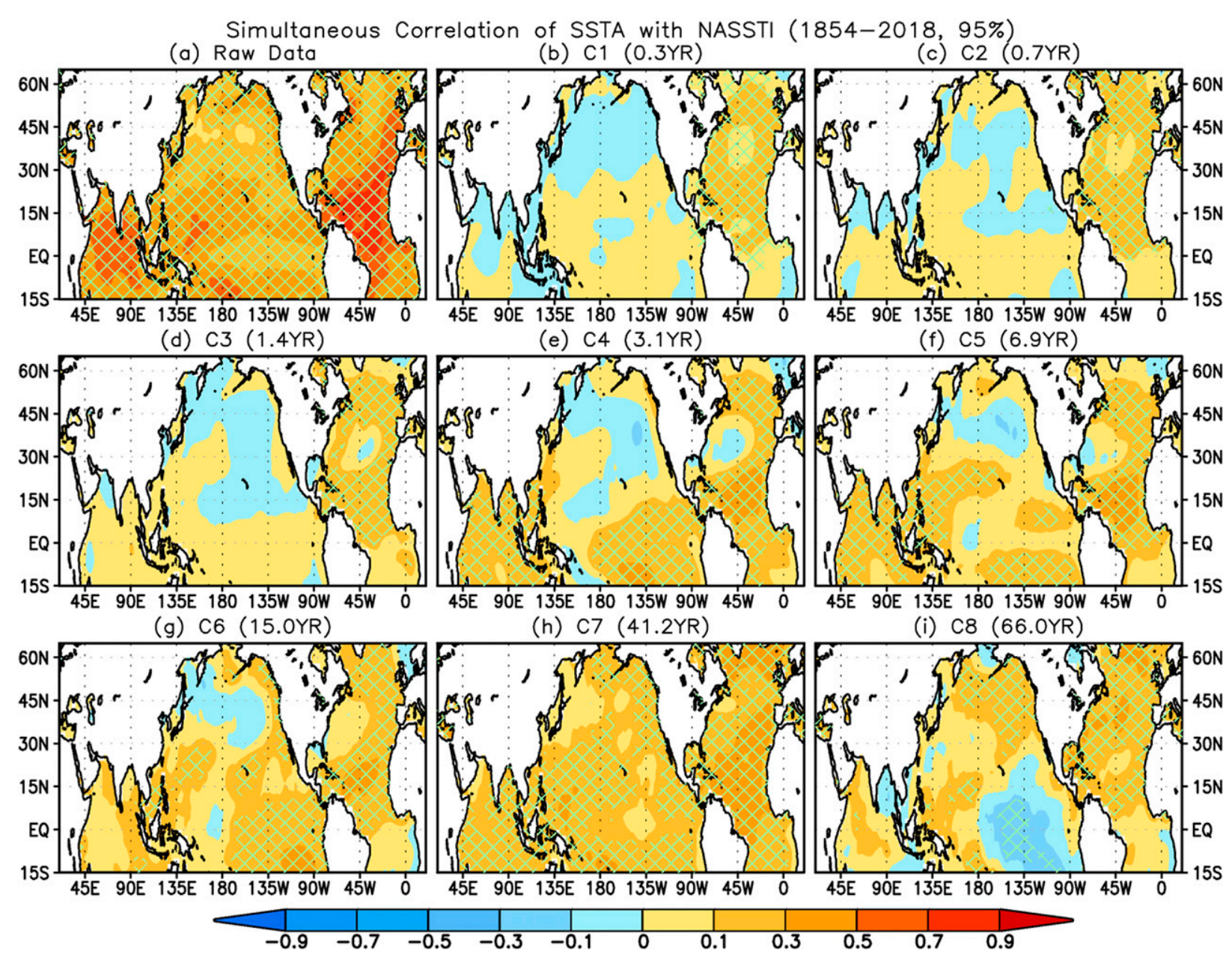

FIG. 3. Simultaneous correlations of monthly mean of raw SSTAs with (a) the raw NASSTI and (b)-(i) the EEMD components. Hatching represents the significant correlations at a $95 \%$ level using a $t$ test with independent sample-size estimations.

variability in the North Atlantic at these time scales may be driven by regional factors, such as the NAO. Based on the similarities of the correlations with SSTA, we add these three components together as subannual variations. The associated physical processes will be examined in section $4 b$.

The NASSTI and its components at different time scales are associated with the SSTA variability in different regions of the North Atlantic. The raw NASSTI well represents SSTA variability in the tropical North Atlantic, which explains $30 \%-40 \%$ of the total variance of monthly mean SSTA in that region (Fig. 4a). For the subannual $(\mathrm{C} 1+\mathrm{C} 2+\mathrm{C} 3)$ and interannual $(\mathrm{C} 4+\mathrm{C} 5)$ components, the maximum variances explained are mainly near $15^{\circ}$ and $50^{\circ} \mathrm{N}$ with amplitudes of $5 \%-10 \%$ for the subannual component (Fig. 4b) and 15\%-20\% for the interannual component (Fig. 4c). For the decadal component (Fig. 4d), the maximum values are along with $15^{\circ} \mathrm{N}$ with an amplitude of less than $10 \%$. For the interdecadal component (Fig. 4e), the two maximum zones are along with $15^{\circ}$ and $60^{\circ} \mathrm{N}$ with values larger than $15 \%$. For the multidecadal component, the large values are in the northern and northwestern North Atlantic Ocean (Fig. 4f). Counting separately, the fraction of the total SSTA variability in the North Atlantic Ocean explained by each of the different components of NASSTI is relatively small. Added together, however, the NASSTI accounts for $30 \%-50 \%$ of the total SSTA variance in large areas of the North Atlantic. It is also noticeable that the spatial patterns of the different components are distinctive of each other, implying different physical mechanisms at work. For instance, in the broad tropics, the subannual variance is confined in the subtropics while the interannual variance extends into the deep tropics. This may be a basic feature of SSTA variability in the North Atlantic. Different from the tropical Pacific, which is dominated by ENSO time-scale variability, there is no dominant time-scale variability in 


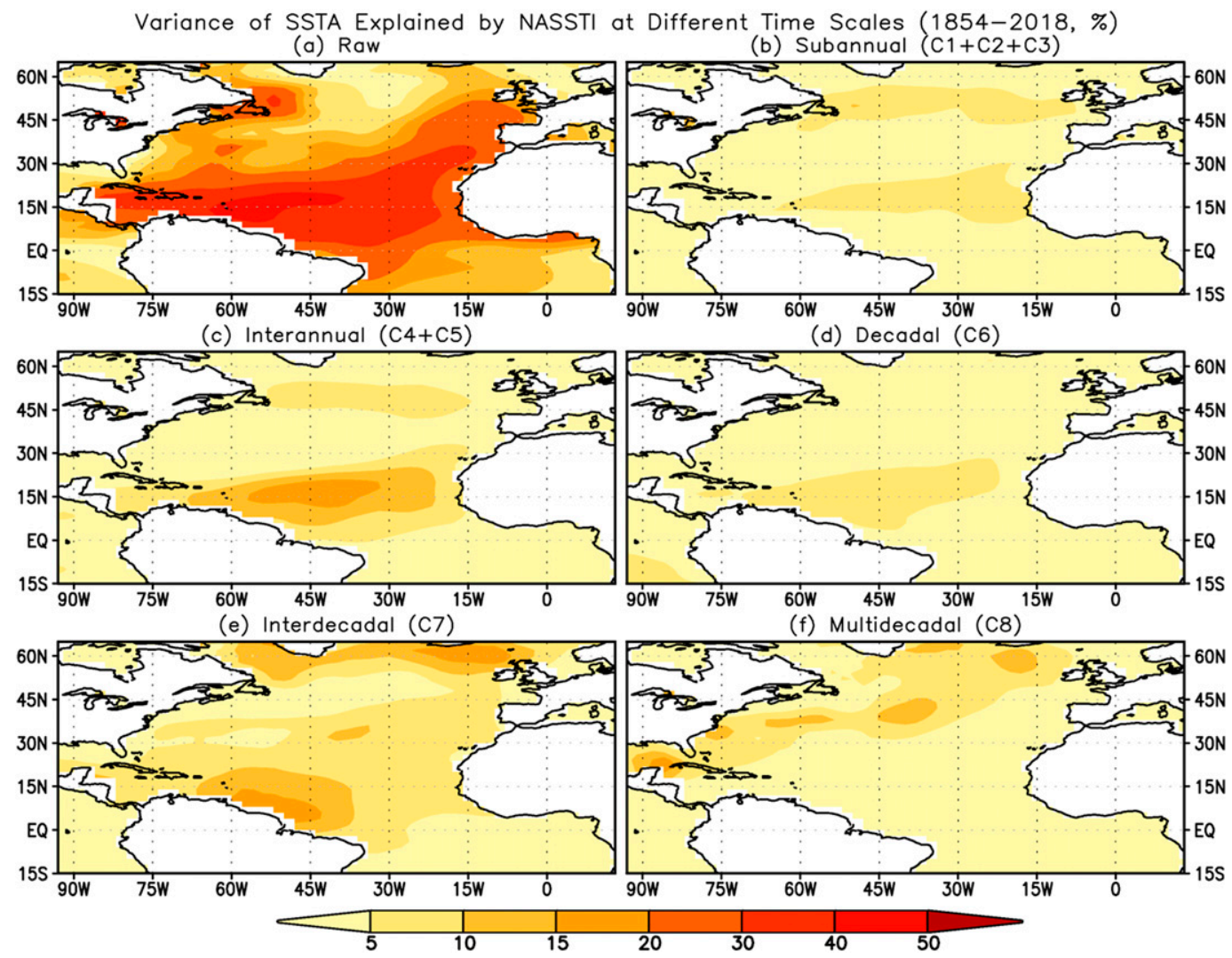

FIG. 4. Percentages of total variance of monthly mean SSTAs explained by the NASSTI at (a) total, (b) subannual $(\mathrm{C} 1+\mathrm{C} 2+\mathrm{C} 3),(\mathrm{c})$ interannual $(\mathrm{C} 4+\mathrm{C} 5),(\mathrm{d})$ decadal (C6), (e) interdecadal (C7), and (f) multidecadal (C8) time scales.

the North Atlantic (Portis et al. 2001; Penland and Hartten 2014).

\section{Associated mechanisms}

\section{a. Interannual variation and impacts of ENSO and $N A O$}

As demonstrated in previous works, the North Atlantic is significantly affected by ENSO (e.g., Enfield and Mayer 1997; Dommenget et al. 2006; Hu and Huang 2007; Hu et al. 2011; Ham et al. 2013; Lübbecke et al. 2018). For example, $\mathrm{Hu}$ et al. (2011) indicated that the maximum positive correlations are seen mainly along the equator and around $30^{\circ} \mathrm{N}$ in the tropical North Atlantic when the Niño-3.4 index leads the North Atlantic SSTA by 3-8 months, and the maximum negative correlations are present mainly along the equatorial Atlantic Ocean when the Niño-3.4 index lags the North Atlantic SSTA by 6-12 months. Such lead-lag correlation may imply that, in addition to the impact of ENSO on the North Atlantic, there is possible feedback of the SSTA in the
North Atlantic on ENSO. Furthermore, SSTAs in the tropical North Atlantic during boreal spring can even serve as a trigger for ENSO event: Cooling (warming) in the tropical North Atlantic in boreal spring favors El Niño (La Niña) development in the following boreal winter (Ham et al. 2013).

To further confirm the connection between NASST and ENSO (Figs. 5a,b), here, we use the interannual components of EEMD of NASSTI to calculate its leadlag correlations with the Niño-3.4 index (Fig. 5d). It is seen that the maximum negative and significant correlation with the amplitude of about 0.3 is present when NASSTI leads the Niño-3.4 index by $13-15$ months. The maximum positive and significant correlation $(\sim 0.4)$ is seen when NASSTI lags the Niño-3.4 index by $7-9$ months. The maximum positive correlation is slightly larger than the maximum negative correlations. These lead-lag correlations (Fig. 5d) may imply a connection between the North Atlantic and ENSO (Cai et al. 2019). Furthermore, the difference of the amplitudes of the positive and negative correlations may be an indicator that the impact of ENSO on the North Atlantic is 
(a) Interannual NASSTI

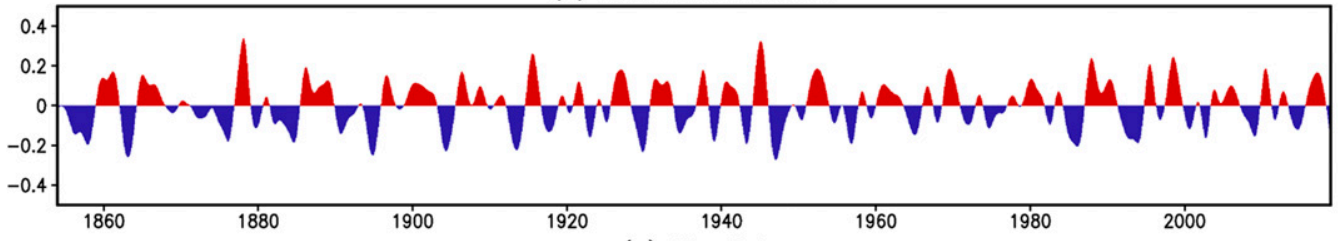

(b) Nino3.4

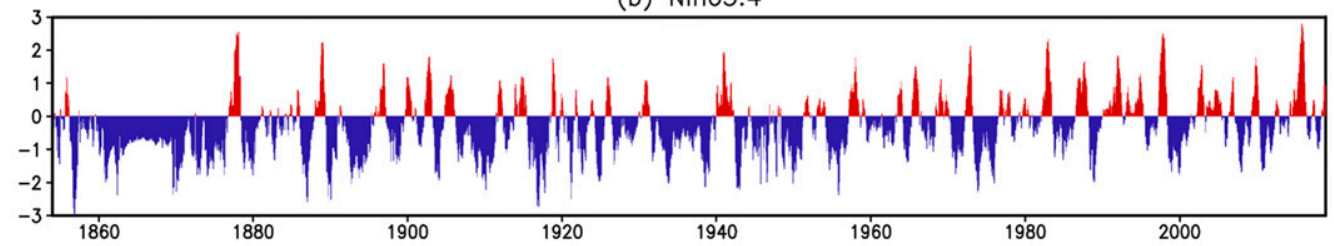

(c) Corr of NAOI \& Interannual NASSTI (95\%)

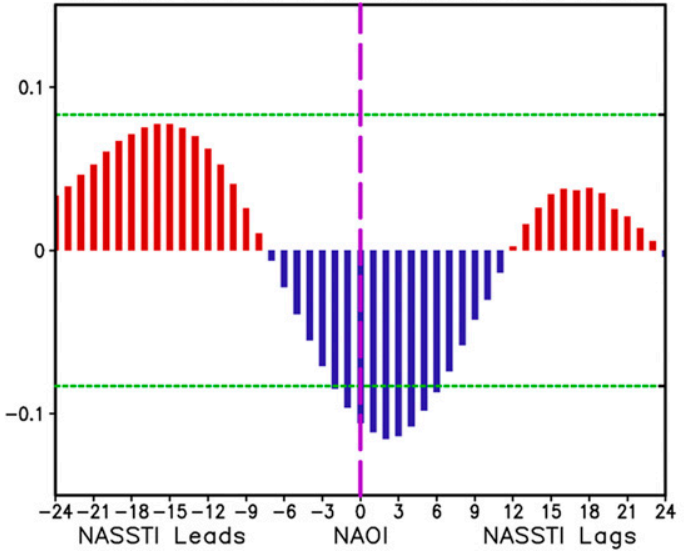

(d) Corr of Nino3.4 \& Interannual NASSTI (95\%)

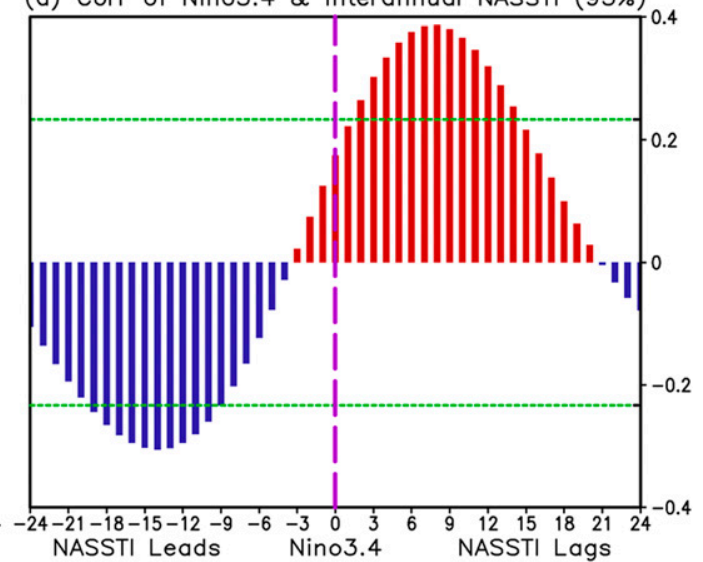

FIG. 5. (a) Interannual component of NASSTI of EEMD results. (b) Niño-3.4 index. (bottom) Lead-lag correlations of the (c) NAO and (d) Niño-3.4 indices with the interannual component of NASSTI. In (c) and (d), the negative (positive) numbers along the $x$ axis represent the number of months that NASSTI leads (lags) the Niño$3.4 / \mathrm{NAO}$ indices, and the horizontal green lines represent the significant correlation at a $95 \%$ level using a $t$ test with independent sample-size estimations.

stronger on average than the impact of the North Atlantic on ENSO. The 7-9 months lag for the impact of ENSO on the North Atlantic may be associated with the fact that ENSO affects the SSTA tendency in the North Atlantic mainly through atmospheric teleconnection and by altering local wind speed and heat flux, then SSTA (Fig. 6). Since the ENSO's influence can persist from 6 months to 2 years, the SSTA response in the North Atlantic Ocean is an accumulation of the persistent and lag impact of ENSO.

For the correlation with the NAOI (Fig. 5c), the maximum negative and significant correlations occur when NASSTI lags the NAOI by $1-3$ months. Compared with the maximum correlation with the Niño-3.4 index (Fig. 5d), the maximum correlation with the NAOI is smaller. This is probably because NAO does not have a dominant frequency and has strong seasonality both in its spatial structure and intensity (Portis et al. 2001). Compared with ENSO, NAO is more variable and closer to a white noise process (Penland and Hartten 2014).
Moreover, the decadal and interdecadal location shift of the action centers of NAO (Hilmer and Jung 2000; Hu and Wu 2004) may be another potential factor leading to the smaller correlation with NAOI. Besides, although the ENSO teleconnection to the North Atlantic has some projections onto the NAO ( $\mathrm{Li}$ and Lau 2012a,b), the absolute values of the correlation between the Niño-3.4 and NAO indices within 12 months lead and lag are smaller than 0.05 (see Fig. 8c of $\mathrm{Hu}$ et al. 2011). For the winter season only, the correlation may be higher. For example, $\mathrm{Li}$ and $\mathrm{Lau}(2012 \mathrm{~b}$ ) showed a correlation of -0.15 between the NAO and Niño-3 indices (see their Table 2), although it is still insignificant at the level of $95 \%$ of a $t$ test. This suggests that the ENSO effect on NAO accounts for a small fraction of the variance of NAO. Two additional potential reasons may be also associated with that the correlation of ENSO with NASSTI is stronger than the correlation of NAOI with NASSTI. First, the ENSO influence is through the Pacific-North American (PNA)-like pattern that mostly affects the tropical North Atlantic 
(a) H500 (Shading) \& Surface UV $\underset{0.5}{\longrightarrow}$ (e) H500 (Shading) \& Surface UV

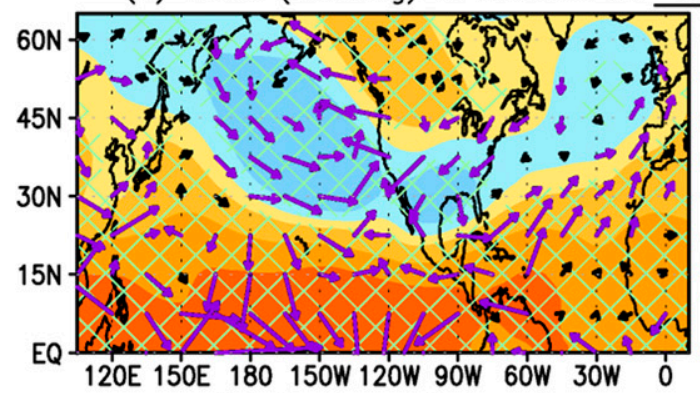

(b) Surface UV Speed
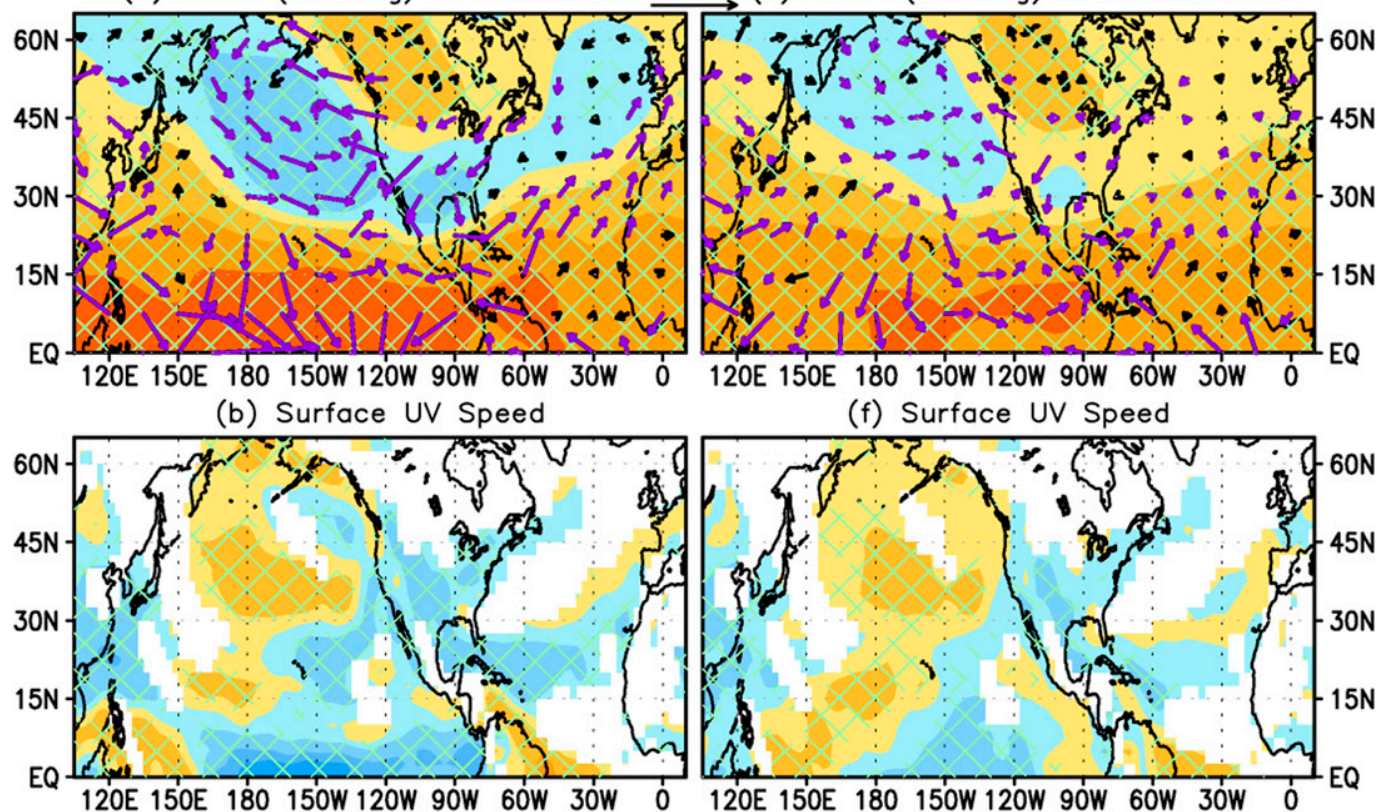

(c) SST

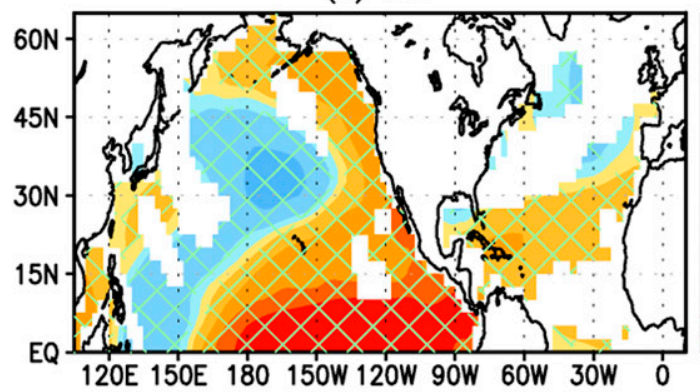

(f) Surface UV Speed

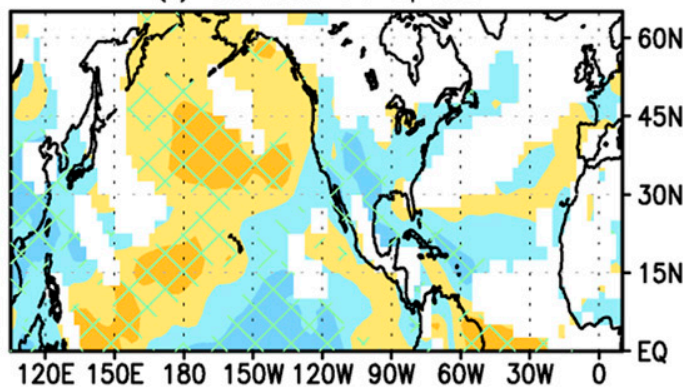

(g) SST

(d) Nino3.4 \& OA Latent Heat Flux

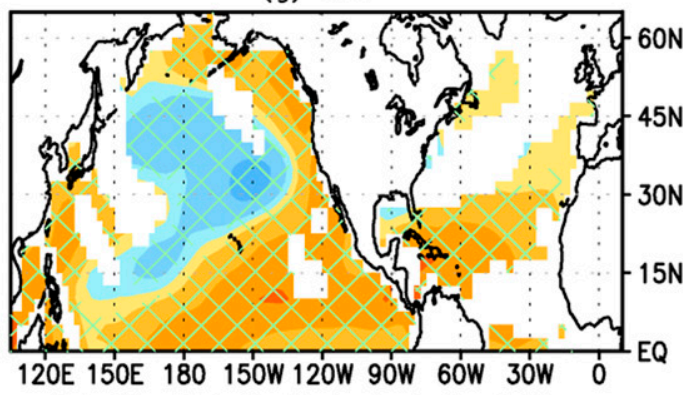

(h) Nino3.4 \& OA Latent Heat Flux
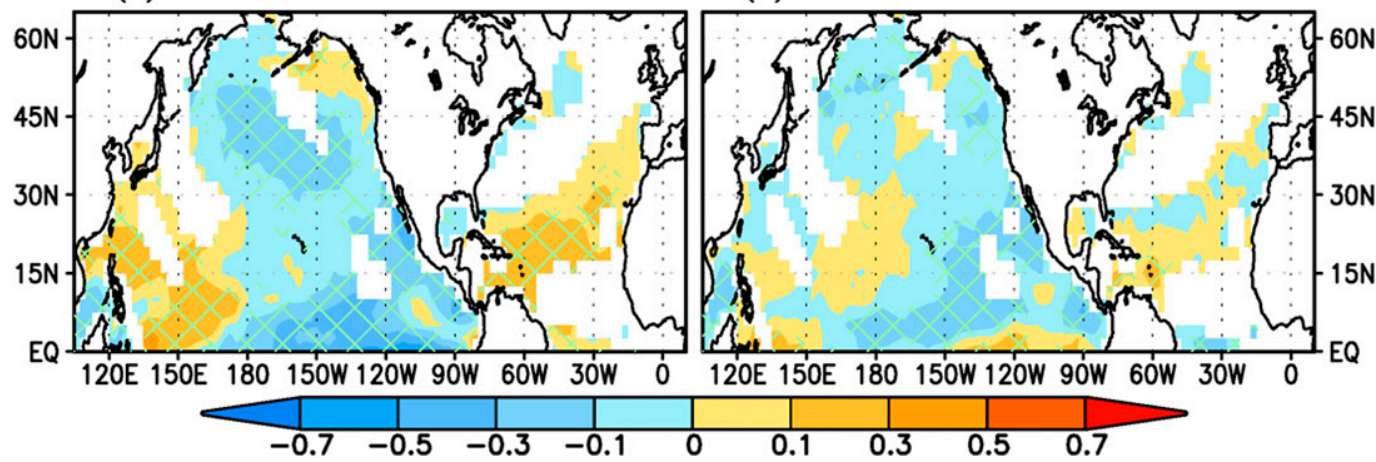

120E 150E 180 150W 120W 90W 60W 30W 
Corr of OML Heat Budget \& dSST/dt \& UV Anomalies with Tendency of Interannual NASSTI (95\%)

(a) Heat Flux

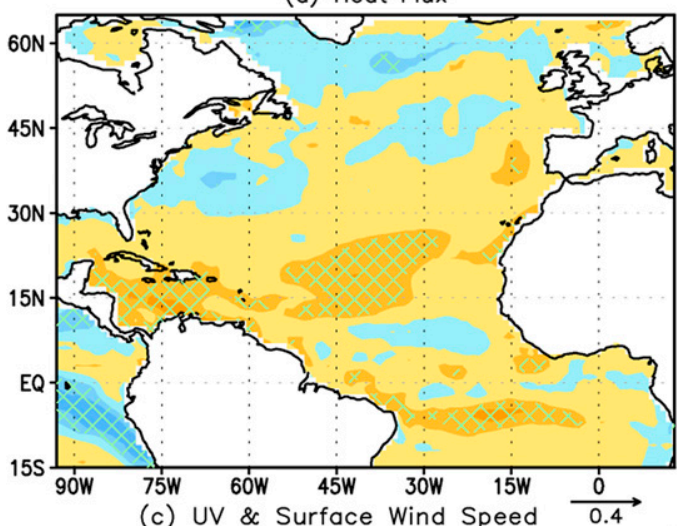

(c) UV \& Surface Wind Speed $\overrightarrow{0.4}$

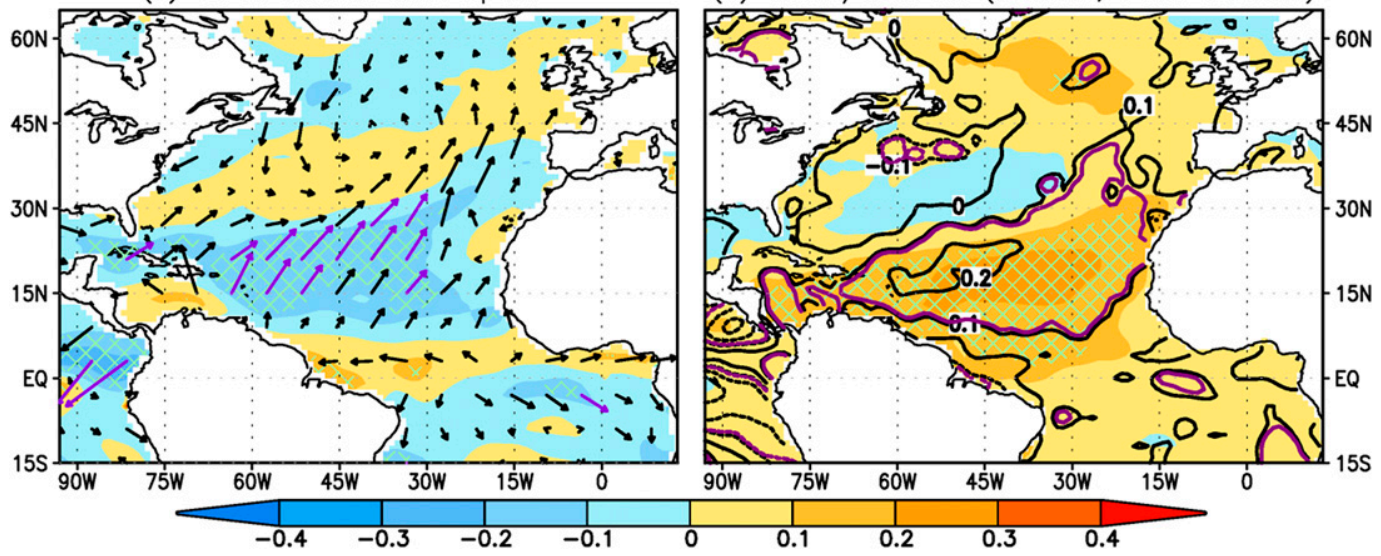

FIG. 7. Simultaneous correlations of the tendency of the interannual component of NASSTI with (a) surface heat flux and (b) dynamical terms of oceanic mixed layer heat budget, (c) surface wind stress and total wind speed anomalies, and (d) SSTA tendency (shading) and latent heat flux (contours) in January 1979-December 2018. The heat flux from the atmosphere to the ocean is positive. Hatching and the purple contour in (d) represent the significant correlations (shading) at a $95 \%$ level using a $t$ test with independent sample-size estimations. The purple vectors represent the significant correlations at a $95 \%$ level using a $t$ test based on the wind speed. reduced contribution while averaged in the entire North Atlantic as the NASSTI.

The changed surface circulation (wind) in the North Atlantic remotely forced by ENSO and/or locally driven by NAO alters surface wind speed and surface heat flux, then SSTA. For example, ENSO affects the North Atlantic Ocean by generating PNA-like circulation anomalies (Figs. 6a,e). Such anomalies are superimposed on the climatological anticyclone (not shown) and, as a result, alters the wind speed and heat flux, and then SSTA (Fig. 6). This scenario is consistent with the correlations of the tendency of the interannual component of NASSTI with surface wind speed, surface heat flux, surface latent heat flux, and the tendency of SSTA (Figs. 7a,c,d).

On the other hand, there are almost no significant simultaneous correlations between the tendency of the interannual component of NASSTI and the dynamical terms of the OML (including zonal advection $Q_{u}$, meridional advection $Q_{v}$, and vertical entrainment and diffusion $Q_{w}$ and $Q_{z z}$ ) in the North Atlantic Ocean (Fig. 7b). In contrast, the latent heat flux and surface wind anomalies are significantly correlated with the tendency of the interannual component of NASSTI (Fig. 7d), which also have a similar spatial pattern of the explained fraction of the variance with larger values along $15^{\circ}$ and $45^{\circ} \mathrm{N}$ and smaller one in between (Fig. 4c). That confirms that, on this time scale, the North Atlantic SSTA variability/ tendency is mainly driven by the thermodynamical processes that are induced by surface wind anomalies through the atmospheric bridge forced remotely by ENSO (Enfield and Mayer 1997; Huang et al. 2002; Hu et al. 2011). For the impact of NAO, both negative and positive SSTAs are generated that depend on regions. The regional averaged SSTA in the North Atlantic largely eliminates the anomaly associated with NAO, resulting in smaller correlations compared with that with ENSO (Figs. 5c,d). Therefore, on interannual time scales, the local surface heat flux anomalies mainly remotely 
NAOI \& NASSTI (Interannual; 95\%)

(a) Jan NAOI

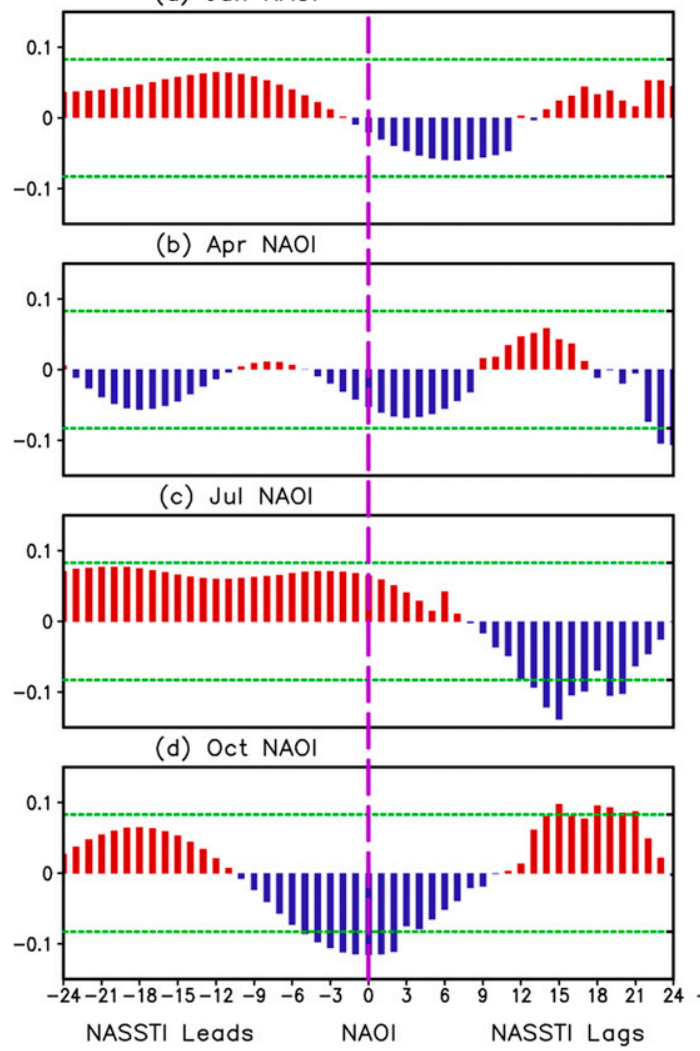

Nino3.4 \& NASSTI (Interannual; 95\%) (e) Jan Nino3.4

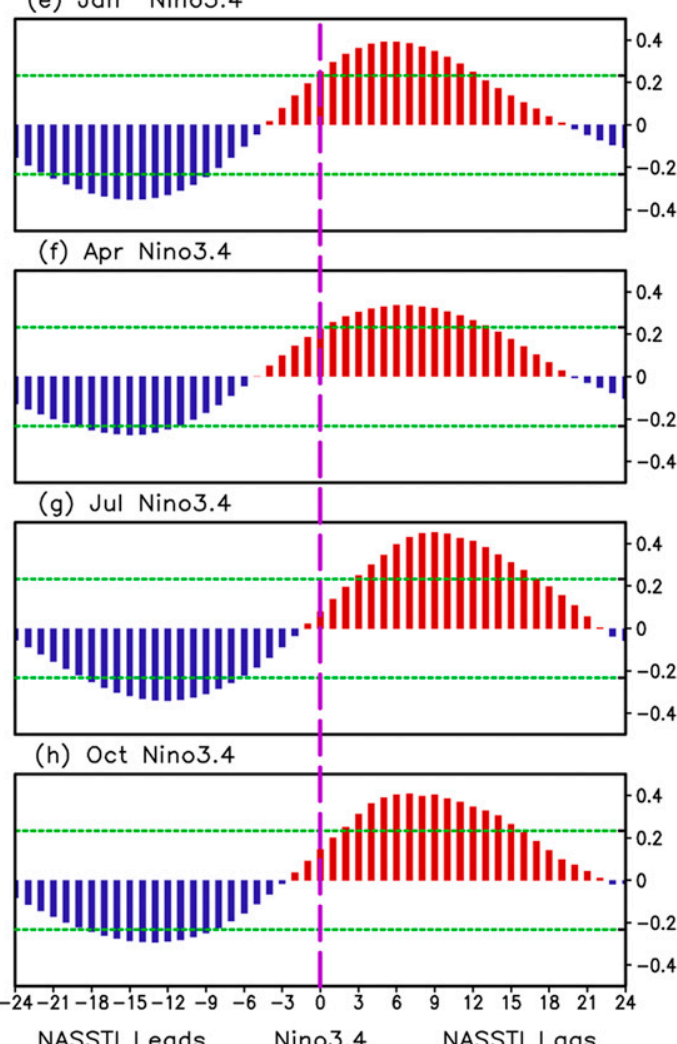

FIG. 8. Lead-lag correlations of (left) the NAO index in (a) January, (b) April, (c) July, and (d) October and (right) the Niño-3.4 index in (e) January, (f) April, (g) July, and (h) October with the interannual component of NASSTI. The negative (positive) numbers along the $x$ axis represent the number of months that NASSTI leads (lags) the Niño-3.4/NAO indices, and the horizontal green lines represent the significant correlation at a $95 \%$ level using a $t$ test with independent sample-size estimations.

forced by ENSO are the leading contributor while the ocean advection terms play a secondary role.

Another crucial reason having the small correlations between NAOI and the interannual component of NASSTI shown in Fig. $5 \mathrm{c}$ is due to the profound seasonality of the correlation. Figures 8a-d show the lead-lag correlation of the interannual component of NASSTI with NAOI in January, April, July, and October, respectively. Both the pattern and amplitude of the lead-lag correlations vary with the month. Although there are detailed differences, the pattern of the lead-lag correlations with October NAOI (Fig. 8d) is mostly comparable with that with all month data (Fig. 5c). For the connection of the tendencies of NASSTI and SSTA in the North Atlantic with surface wind speed and heat flux anomalies, it is strongest in winter (January, Fig. 9a), weakest in summer (July, Fig. 9c), and in between in spring (April, Fig. 9b) and fall (October, Fig. 9d), implying that it is more important for NAO associated atmospheric circulation in altering the SSTA in the North Atlantic via modifying wind speed and heat flux in the cold season than in the warm season. In contrast, the lead-lag corrections between the Niño-3.4 index and the interannual component of NASSTI have much smaller seasonality and are also more robust and significant (Figs. 8e-h).

\section{b. Subannual variation and association with NAO}

For the subannual variation of NASSTI (Fig. 10a), significant negative correlations are present when the NAOI (Fig. 10b) leads NASSTI by 0-3 months (Fig. 10c). It has been documented that the direct oceanic response to NAO is a so-called tripole pattern (e.g., Marshall et al. 2001), which prevails in winter when the NAO is strongest. For example, during a positive phase of NAO, the associated strong, cold, dry westerlies over the Labrador Seas lead to stronger heat loss and cooler SSTs; meanwhile, the associated strengthening of the Azores high results in warm-air advection over the western Atlantic. Considering the basin as a whole, the positive (negative) phase of NAO is associated with net negative (positive) SSTAs. Compared with the ocean response to NAO, the feedback of the local SSTAs on the atmospheric circulation (NAO) is relatively 
Corr with Tendency of Interannual NASSTI (95\%)

(a) January
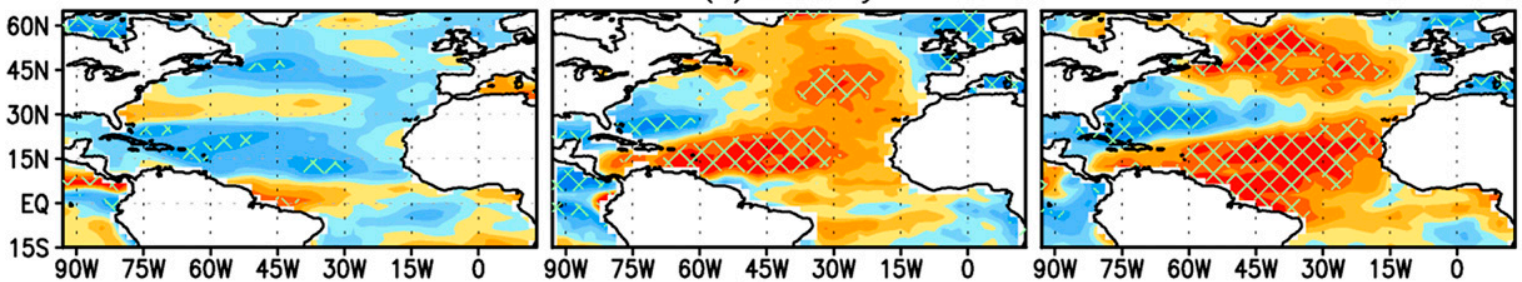

(b) April
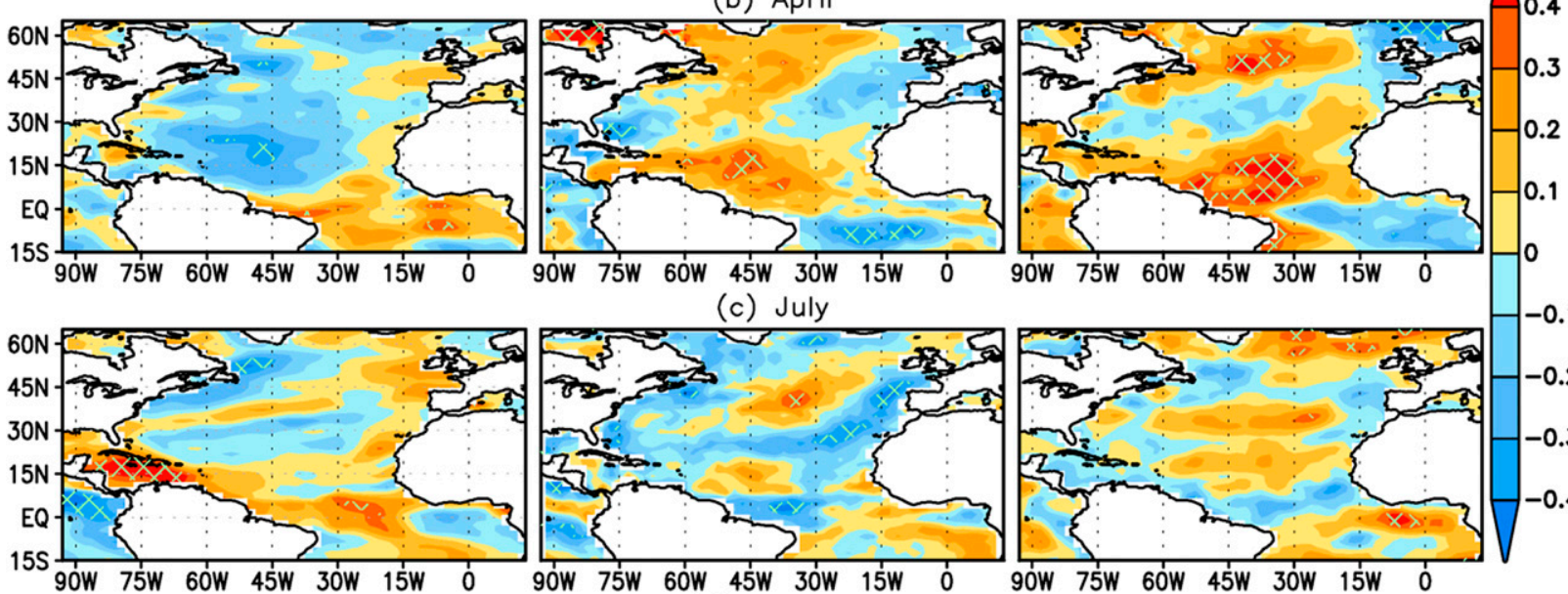

(c) July
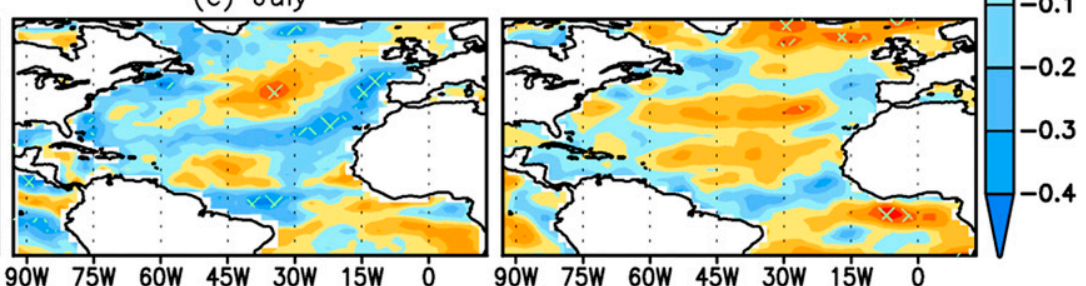

(d) October
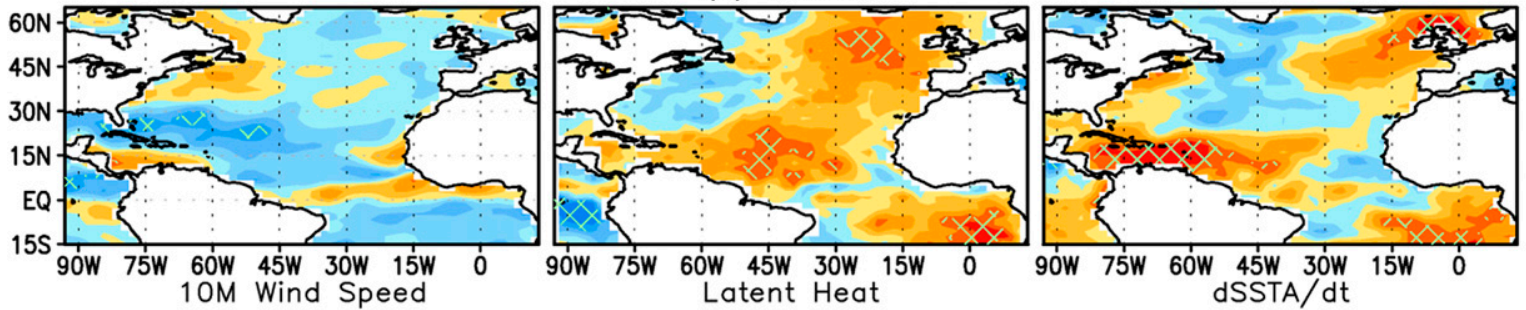

FIG. 9. Simultaneous correlations of the temporal tendency of the interannual component of NASSTI with (left) wind speed at $10 \mathrm{~m}$, (center) latent heat flux, and (right) SSTA tendency in (a) January, (b) April, (c) July, and (d) October. Hatching represents the significant correlation at a $95 \%$ level using a $t$ test.

smaller (Visbeck et al. 2003; Hu and Huang 2006; Hu et al. 2011). Such feedback may be partially associated with the so-called reemergence mechanism (Namias and Born 1970; Alexander and Deser 1995; Timlin et al. 2002) that takes effect just in some years (Hu and Huang 2006).

Also, there are some marginally significant negative correlations when NASSTI leads the Niño-3.4 index by 5-6 months (Fig. 10d). That may be similar to the interannual component of NASSTI (Fig. 5d) and suggest a weak impact of NASST on ENSO. However, all the correlations are small although some of them are significant. This implies that a small fraction of the SSTA variability in the North Atlantic Ocean at subannual time scale is connected with either ENSO or NAO, while a majority of the SSTA variability is driven by other factors.

The mechanism of the variations in the tropical North Atlantic Ocean associated with the NASSTI at subannual time scale (Fig. 11) is similar to that at interannual time scale (Fig. 7). The anomalous cyclonic atmospheric circulation (wind) anomalies (Fig. 11c) modify the surface latent heat flux (Fig. 11a; contours in Fig. 11d), then change the SSTA variations (Fig. 11d). Different from the interannual time scale of NASSTI (Fig. 7b), there are some significant correlations with dynamical processes (Fig. 11b), although it is smaller than that with the heat flux (Fig. 11a), suggesting that in addition to the thermodynamical processes, the dynamical processes may also play a role. Among the dynamical processes, the contribution of the zonal advection $Q_{u}$ is small (Fig. 12a). The meridional term $Q_{v}$ is mainly associated with a dipole-like variation between the subtropics $\left(10^{\circ}-\right.$ $\left.30^{\circ} \mathrm{N}\right)$ and midlatitude $\left(35^{\circ}-55^{\circ} \mathrm{N}\right)$ of the North Atlantic (Fig. 12b), which is likely due to the Ekman heat transport considering the surface wind correlation 
(a) Subannual NASSTI
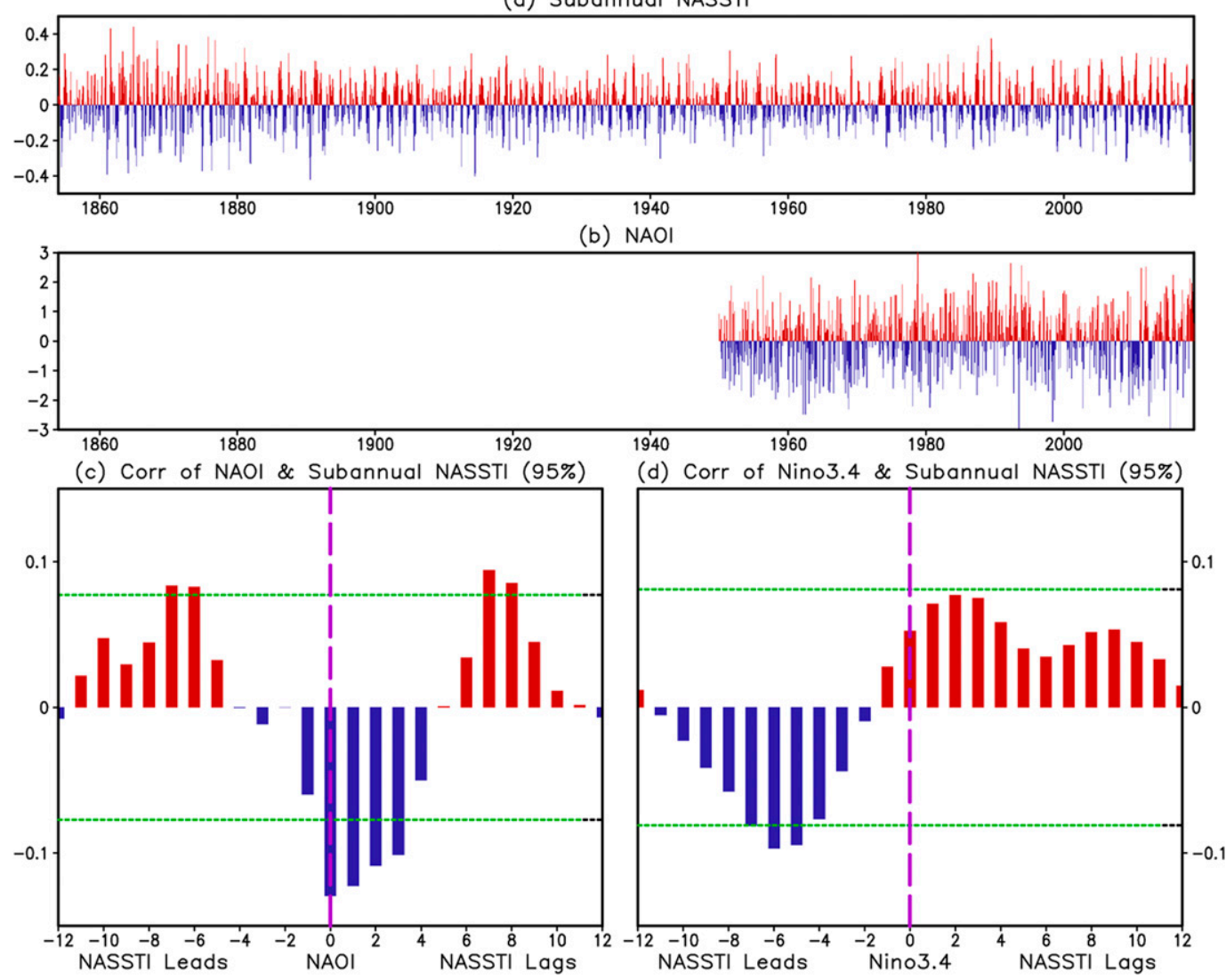

FIG. 10. (a) Subannual component of NASSTI of EEMD results. (b) NAOI. (bottom) Lead-lag correlations of the (c) NAO and (d) Niño-3.4 indices with the subannual component of NASSTI. In (c) and (d), the negative (positive) numbers along the $x$ axis represent the number of months that NASSTI leads (lags) the Niño-3.4/NAO indices, and the horizontal green lines represent the significant correlation at a $95 \%$ level using a $t$ test with independent sample-size estimations.

pattern in Fig. 11c. The vertical entrainment $Q_{w}$ contributes to the contrast between the western and eastern North Atlantic Ocean in $20^{\circ} \mathrm{N}$ northward (shading in Fig. 12c). The vertical diffusion term $Q_{z z}$ mainly results in damping in the northeastern Atlantic Ocean (Fig. 12d).

When NAO is in a positive phase, anomalous anticyclone presents in the North Atlantic Ocean (Fig. 13c). Superimposed on the climatological anticyclone, surface wind speed increases in the tropics and $45^{\circ}-60^{\circ} \mathrm{N}$ and decreases in between (shading in Fig. 13c), which alters the surface heat flux (Fig. 13a) and SSTA tendency (Fig. 13d), a scenario similar to that shown in Fig. 11. However, the spatial distributions of the connections with the NASSTI at subannual time scale are more like a horseshoe-like pattern (Fig. 11), while it is more like a tripole pattern for the correlations with NAOI (Fig. 13). As discussed in section 3, the horseshoe-like pattern drives NAO (Czaja and Frankignoul 1999, 2002), and the tripole pattern is mainly a response to $\mathrm{NAO}$ (Cayan
1992; Marshall et al. 2001; Czaja and Frankignoul 2002; Deser et al. 2010; Hurrell and Deser 2010). Thus, in addition to the driving of NAO (Fig. 10c), SSTA variability at subannual time scale in the North Atlantic may have some feedback on NAO variability through dynamical and thermodynamical processes (e.g., $\mathrm{Hu}$ et al. 2011).

One question is why the correlations are more significant for the subannual component of NASSTI, but the explained fraction of the total variance in the tropical North Atlantic is smaller (Figs. 11 and 4b) compared with that of the interannual component of NASSTI (Figs. 7 and $4 \mathrm{c}$ ). We speculate that may be associated with the time scales. The subannual component of the NASSTI is mainly associated with the month-to-month SST fluctuations, which can be generated by the latent surface heat fluxes as demonstrated by Cayan (1992). That is largely consistent with the significant correlations of NASSTI with heat flux, SSTA, and surface wind 
Corr of OML Heat Budget \& dSST/dt \& UV Anomalies with Tendency of Subannual NASSTI (95\%)

(a) Heat Flux
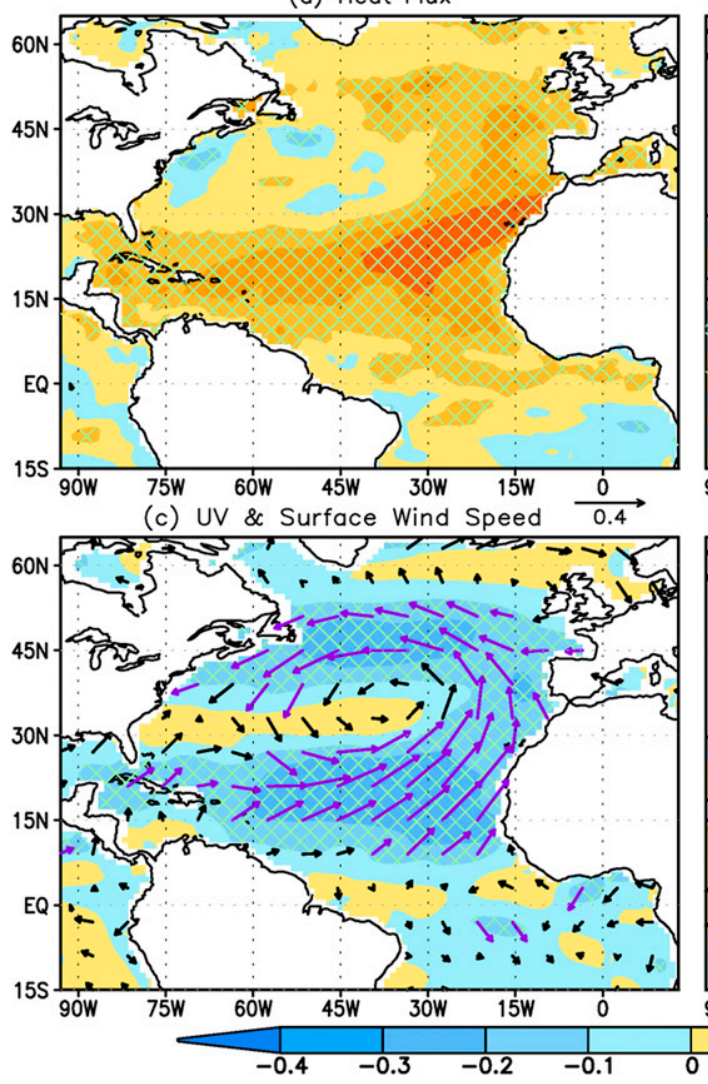

FIG. 11. Simultaneous correlations of the tendency of the subannual component of NASSTI with (a) surface heat flux and (b) dynamical terms of oceanic mixed layer heat budget, (c) surface wind stress and total wind speed anomalies, and (d) SSTA tendency (shading) and latent heat flux (contours) in January 1979-December 2018. The heat flux from the atmosphere to the ocean is positive. Hatching in (a)-(d) and the purple contour in (d) represent the significant correlations (shading) at a $95 \%$ level using a $t$ test with independent sample-size estimations. The purple vectors represent the significant correlations at a $95 \%$ level using a $t$ test based on the wind speed. shown in Fig. 11, except that we also demonstrate some contribution of the oceanic heat transport, probably due to wind-induced Ekman flow. However, the highfrequency feature of this component may not provide enough time for the SST anomalies to grow. As a result, the magnitude of the SST anomalies on this time scale may not be large and the explained fraction of the total variance is small. This is a typical case of atmosphere forcing the ocean. On the interannual time scale, however, the lower-frequency feature of this component allows a longer time for the SSTA to grow to a larger magnitude and to persist longer eventually. As a result, the variance is larger on this time scale.

\section{Summary and discussion}

In this work, the multi-time-scale feature of the SSTA variability in the North Atlantic and their connections with ENSO and NAO as well as the mechanisms are examined. It is noted that the SSTA variability in the North Atlantic has a profound peak around 66 years, and it is referred to as AMO. Meanwhile, in addition to long-term trend and the AMO time-scale variation, the SSTA in the North Atlantic at subannual and interannual time scales is nonnegligible, suggesting that the North Atlantic SSTA fluctuates on multiple time scales and is potentially associated with different mechanisms.

About $20 \%$ of the interannual time-scale variance of NASST can be accounted for as a lagged response to ENSO. Compared with influence of NAO, ENSO has a greater impact. However, a large fraction of the interannual variance of NASST is mainly driven by the atmospheric noise, which may be unrelated to either ENSO or NAO. The interannual component of NASST is significantly correlated with the Niño-3.4 index. The correlation is moderate and negative and reaches the 


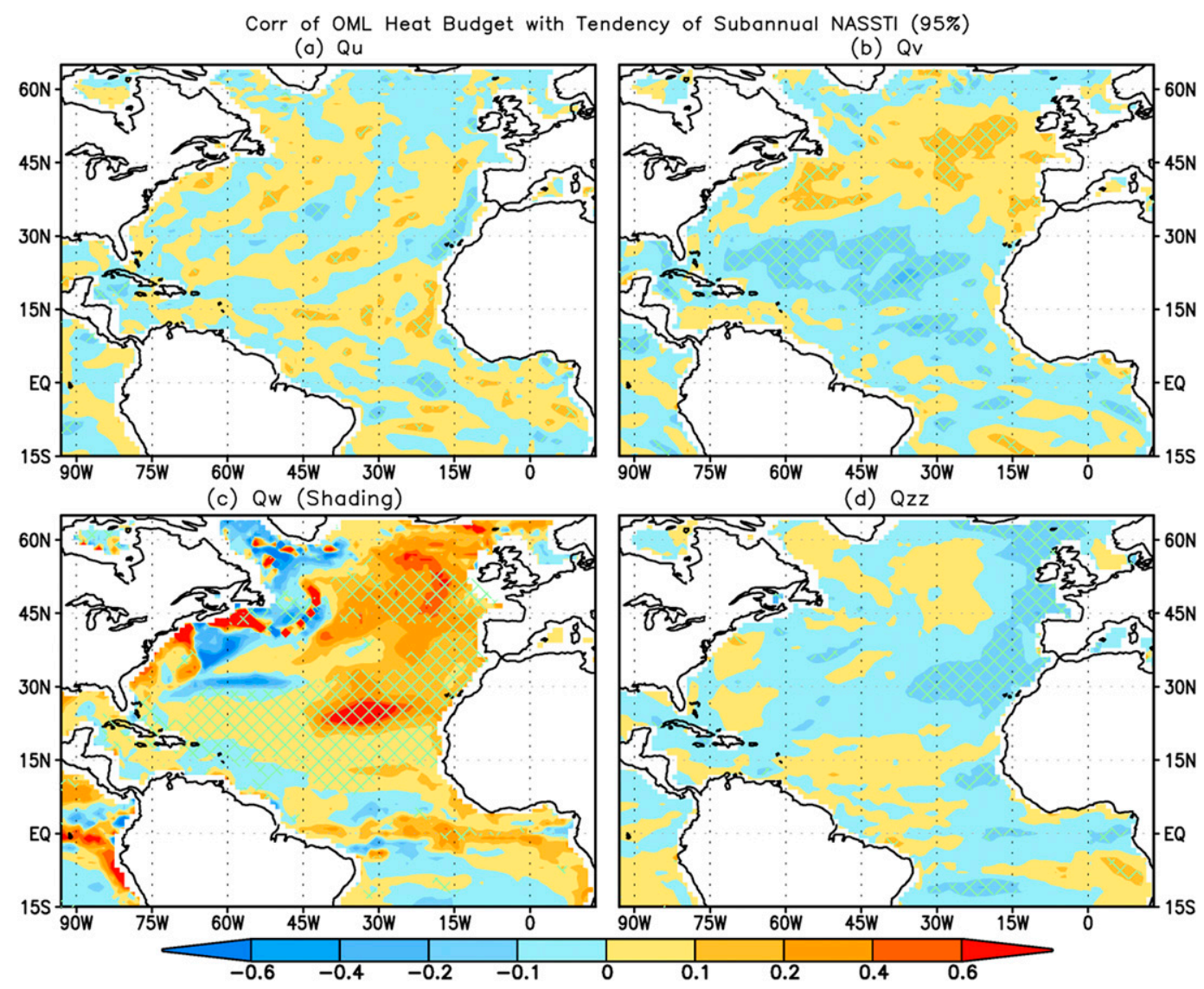

FIG. 12. Simultaneous correlations of the tendency of the subannual component of NASSTI with the oceanic mixed layer heat budget terms (a) $Q_{u}$, (b) $Q_{v}$, (c) $Q_{w}$, and (d) $Q_{z z}$ in January 1979-December 2018. Hatching represents the significant correlations at a $95 \%$ level using a $t$ test with independent sample-size estimations.

maximum when NASSTI leads the Niño-3.4 index by 13-15 months. The correlations are significant and positive and reaching the maximum when NASSTI lags the Niño-3.4 index by 7-9 months. Such results may imply a connection between the NASST and ENSO. Statistically, the impact of ENSO on the NASST is stronger than the impact of NASST on ENSO. The changed atmospheric circulation remotely forced by ENSO and/or locally driven by NAO alters the surface heat flux over the North Atlantic Ocean. Thus, at subannual time scale, the variation of the NASST is weakly driven only by NAO, but not by ENSO. The associated thermodynamical processes are similar to that associated with the interannual time-scale component of the NASST; however, the dynamical processes have a significant contribution to the subannual time-scale component but not to the interannual time-scale component. Geographically, the contribution from the dynamical processes is comparable to that from the thermodynamical processes in the mid- and high latitudes.
The North Atlantic SSTA tripole pattern, an important part of the SSTA variations in the region, associated with the NAO did not appear in any of the correlations between SSTAs and NASSTI (e.g., Seager et al. 2000; Czaja and Frankignoul 2002). In this analysis, the North Atlantic horseshoe pattern emerges instead. When taking the average over the whole North Atlantic basin as in the definition of NASSTI, the out of phase variations of the tripole tend to mutually cancel, which leads to this signal to be weakened in the resulting time series. This leads to both the absence of the tripole and the low correlations to the NAOI.

Last, we should point out that the data are too short, in particular, for examining the decadal to multidecadal variations. That may affect the robustness of some results to a certain extent. Also, here all the anomalies are referred to that in all months. The seasonality of the variability of SSTA in the North Atlantic and their associated physical processes are a future research topic. The pronounced seasonality of the climate in the North 

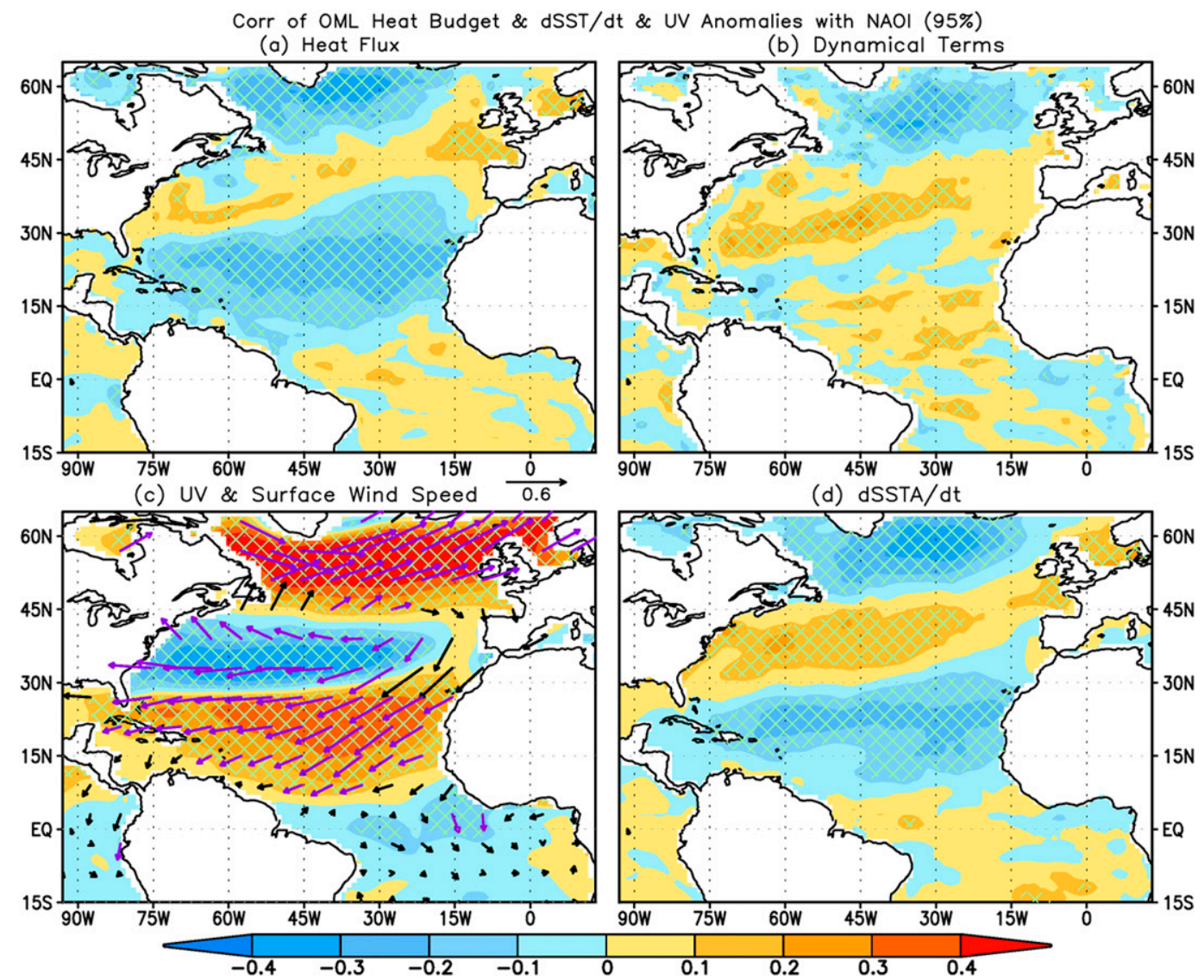

FIG. 13. Simultaneous correlations of the NAOI with (a) surface heat flux and (b) dynamical terms of oceanic mixed layer heat budget, (c) surface wind stress and total wind speed anomalies, and (d) SSTA tendency in January 1979-December 2018. Hatching represents the significant correlations at a 95\% level using a $t$ test with independent sample-size estimations. The purple vectors represent the significant correlations at a $95 \%$ level using a $t$ test based on the wind speed.

Atlantic may be associated with the fact that there is a broad frequency band of variations (Fig. 1) and also small fractions of the total variance can be explained by each of different time-scale components (Fig. 4). It is expected that such seasonality may imply different mechanisms involved.

Acknowledgments. We appreciate the constructive comments and suggestions from three reviewers and Editor Dr. Amy Clement, which helped us significantly improve the quality of this work. The procedure of the oceanic heat budget calculation used in this work was developed by Dr. Boyin Huang and is maintained by Dr. C. Wen. For data used in this study, please contact us via xiaofanli@zju.edu.cn. Xiaofan Li was supported by the National Natural Science Foundation of China (41930967 and 41775040) and the National Key Basic Research and Development Project of China (2015CB953601). Bohua Huang is supported by grants from NSF (AGS-1338427), NASA (NNX14AM19G), and NOAA (NA14OAR4310160 and NA17OAR4310144).

\section{REFERENCES}

Alexander, M. A., and C. Deser, 1995: A mechanism for the recurrence of wintertime midlatitude SST anomalies. J. Phys. Oceanogr., 25, 122-137, https://doi.org/10.1175/1520-0485(1995) $025<0122$ :AMFTRO $>2.0 . \mathrm{CO} ; 2$.

Álvarez-García, F., M. Latif, and A. Biastoch, 2008: On multidecadal and quasi-decadal North Atlantic variability. J. Climate, 21, 34333452, https://doi.org/10.1175/2007JCLI1800.1.

—, M. J. OrtizBevia, and W. D. CabosNarvaez, 2011: On the structure and teleconnections of North Atlantic decadal variability. J. Climate, 24, 2209-2223, https://doi.org/10.1175/ 2011JCLI3478.1.

Barnston, A. G., and R. E. Livezey, 1987: Classification, seasonality and persistence of low-frequency atmospheric circulation patterns. Mon. Wea. Rev., 115, 1083-1126, https://doi.org/ 10.1175/1520-0493(1987)115<1083:CSAPOL > 2.0.CO;2.

Behringer, D. W., 2007: The Global Ocean Data Assimilation System (GODAS) at NCEP. 11th Symp. on Integrated Observing and 
Assimilation Systems for the Atmosphere, Oceans, and Land Surface (IOAS-AOLS), San Antonio, TX, Amer. Meteor. Soc., 3.3, http:// ams.confex.com/ams/87ANNUAL/techprogram/paper_119541.htm.

Bretherton, C. S., M. Widmann, V. P. Dymnikov, J. M. Wallace, and I. Bladé, 1999: The effective number of spatial degrees of freedom of a time-varying field. J. Climate, 12, 1990-2009, https://doi.org/ 10.1175/1520-0442(1999)012<1990:TENOSD > 2.0.CO;2.

Brown, P. T., M. S. Lozier, R. Zhang, and W. Li, 2016: The necessity of cloud feedback for a basin-scale Atlantic Multidecadal Oscillation. Geophys. Res. Lett., 43, 3955-3963, https://doi.org/10.1002/2016 GL068303.

Cai, W., and Coauthors, 2019: Pantropical climate interactions. Science, 363, eaav4236, https://doi.org/10.1126/science.aav4236.

Cane, M. A., A. C. Clement, L. N. Murphy, and K. Bellomo, 2017: Low-pass filtering, heat flux, and Atlantic multidecadal variability. J. Climate, 30, 7529-7553, https://doi.org/10.1175/ JCLI-D-16-0810.1.

Cayan, D. R., 1992: Latent and sensible heat flux anomalies over the northern oceans: Driving the sea surface temperature. J. Phys. Oceanogr., 22, 859-881, https://doi.org/10.1175/15200485(1992)022<0859:LASHFA > 2.0.CO;2.

Chylek, P., and G. Lesins, 2008: Multidecadal variability of Atlantic hurricane activity: 1851-2007. J. Geophys. Res., 113, D22106, https://doi.org/10.1029/2008JD010036.

Clement, A., K. Bellomo, L. N. Murphy, M. A. Cane, T. Mauritsen, G. Rädel, and B. Stevens, 2015: The Atlantic Multidecadal Oscillation without a role for ocean circulation. Science, $\mathbf{3 5 0}$, 320-324, https://doi.org/10.1126/science.aab3980.

Czaja, A., and C. Frankignoul, 1999: Influence of the North Atlantic SST on the atmospheric circulation. Geophys. Res. Lett., 26, 2969-2972, https://doi.org/10.1029/1999GL900613.

_ , and J. Marshall, 2001: Observations of atmosphere-ocean coupling in the North Atlantic. Quart. J. Roy. Meteor. Soc., 127, 1893-1916, https://doi.org/10.1002/qj.49712757603.

—, and C. Frankignoul, 2002: Observed impact of Atlantic SST anomalies on the North Atlantic Oscillation. J. Climate, 15, 606623, https://doi.org/10.1175/1520-0442(2002)015<0606:OIOASA > 2.0.CO;2.

Deser, C., and M. L. Blackmon, 1993: Surface climate variations over the North Atlantic Ocean during winter: 1900-1989. J. Climate, 6, 1743-1753, https://doi.org/10.1175/1520-0442 (1993)006<1743:SCVOTN $>2.0 . C O ; 2$.

— M. A. Alexander, S.-P. Xie, and A. S. Phillips, 2010: Sea surface temperature variability: Patterns and mechanisms. Annu. Rev. Mar. Sci., 2, 115-143, https://doi.org/10.1146/ annurev-marine-120408-151453.

Dommenget, D., V. Semenov, and M. Latif, 2006: Impacts of the tropical Indian and Atlantic Oceans on ENSO. Geophys. Res. Lett., 33, L11701, https://doi.org/10.1029/2006GL025871.

Enfield, D. B., and D. A. Mayer, 1997: Tropical Atlantic sea surface temperature variability and its relation to El Niño-Southern Oscillation. J. Geophys. Res., 102, 929-945, https://doi.org/ 10.1029/96JC03296.

_ A. M. Mestas-Nunez, and P. J. Trimble, 2001: The Atlantic Multidecadal Oscillation and its relation to rainfall and river flows in the continental U.S. Geophys. Res. Lett., 28, 20772080, https://doi.org/10.1029/2000GL012745.

Frankcombe, L. M., A. Von Der Heydt, and H. A. Dijkstra, 2010: North Atlantic multidecadal climate variability: An investigation of dominant time scales and processes. J. Climate, 23, 3626-3638, https://doi.org/10.1175/2010JCLI3471.1.

Garuba, O. A., J. Lu, H. A. Singh, F. Liu, and P. Rasch, 2018: On the relative roles of the atmosphere and ocean in the Atlantic multidecadal variability. Geophys. Res. Lett., 45, 9186-9196, https://doi.org/10.1029/2018GL078882.

Guan, B., and S. Nigam, 2009: Analysis of Atlantic SST variability factoring interbasin links and the secular trend: Clarified structure of the Atlantic multidecadal oscillation. J. Climate, 22, 4228-4240, https://doi.org/10.1175/2009JCLI2921.1.

Gulev, S. K., M. Latif, N. Keenlyside, W. Park, and K. P. Koltermann, 2013: North Atlantic Ocean control on surface heat flux on multidecadal timescales. Nature, 499, 464-467, https://doi.org/10.1038/nature12268.

Ham, Y.-G., J.-S. Kug, J.-Y. Park, and F.-F. Jin, 2013: Sea surface temperature in the north tropical Atlantic as a trigger for El Niño/Southern Oscillation events. Nat. Geosci., 6, 112-116, https://doi.org/10.1038/ngeo1686.

Hilmer, M., and T. Jung, 2000: Evidence for a recent change in the link between the North Atlantic Oscillation and Arctic Sea ice export. Geophys. Res. Lett., 27, 989-992, https://doi.org/ 10.1029/1999GL010944.

$\mathrm{Hu}, \mathrm{Z} . \mathrm{Z}$., and Z. Wu, 2004: The intensification and shift of the annual North Atlantic Oscillation in a global warming scenario simulation. Tellus, 56A, 112-124, https://doi.org/10.3402/ tellusa.v56i2.14403.

_- and B. Huang, 2006: On the significance of the relationship between the North Atlantic Oscillation in early winter and Atlantic sea surface temperature anomalies. J. Geophys. Res., 111, D12103, https://doi.org/10.1029/2005JD006339.

—, and —, 2007: The predictive skill and the most predictable pattern in the tropical Atlantic: The effect of ENSO. Mon. Wea. Rev., 135, 1786-1806, https://doi.org/10.1175/MWR3393.1.

— A. Kumar, B. Huang, Y. Xue, W. Wang, and B. Jha, 2011: Persistent atmospheric and oceanic anomalies in the North Atlantic from summer 2009 to summer 2010. J. Climate, 24, 5812-5830, https://doi.org/10.1175/2011JCLI4213.1.

,$--\frac{-}{-}$, and -2016 : Spatial distribution and the interdecadal change of leading modes of heat budget of the mixed-layer in the tropical Pacific and the association with ENSO. Climate Dyn., 46, 1753-1768, https://doi.org/10.1007/s00382-015-2672-4.

Huang, B., P. S. Schopf, and Z. Pan, 2002: The ENSO effect on the tropical Atlantic variability: A regionally coupled model study. Geophys. Res. Lett., 29, 2039, https://doi.org/10.1029/ 2002GL014872.

_ Y. Y. Xue, D. Zhang, A. Kumar, and M. J. McPhaden, 2010: The NCEP GODAS ocean analysis of the tropical Pacific mixed layer heat budget on seasonal to interannual time scales. J. Climate, $\mathbf{2 3}$, 4901-4925, https://doi.org/10.1175/2010JCLI3373.1.

— Z. Z.Z. Hu, J. L. Kinter III, Z. Wu, and A. Kumar, 2012: Connection of stratospheric QBO with global atmospheric general circulation and tropical SST. Part I: Methodology and composite life cycle. Climate Dyn., 38, 1-23, https://doi.org/ 10.1007/s00382-011-1250-7.

- , and Coauthors, 2015: Climate drift of AMOC, North Atlantic salinity and Arctic sea ice in CFSv2 decadal predictions. Climate Dyn., 44, 559-583, https://doi.org/10.1007/s00382-014-2395-y.

_ Temperature version 5 (ERSSTv5): Upgrades, validations, and intercomparisons. J. Climate, 30, 8179-8205, https:// doi.org/10.1175/JCLI-D-16-0836.1.

Huang, N. E., and Z. Wu, 2008: A review on Hilbert-Huang transform: Method and its applications to geophysical studies. Rev. Geophys., 46, RG2006, https://doi.org/10.1029/2007RG000228.

Hurrell, J. W., 1995: Decadal trends in the North Atlantic Oscillation: Regional temperatures and precipitation. Science, 269, 676-679, https://doi.org/10.1126/science.269.5224.676. 
— - and C. Deser, 2010: North Atlantic climate variability: The role of the North Atlantic Oscillation. J. Mar. Syst., 79, 231244, https://doi.org/10.1016/j.jmarsys.2009.11.002.

— , Y. Kushnir, G. Ottersen, and M. Visbeck, 2003: An overview of the North Atlantic Oscillation. The North Atlantic Oscillation: Climate Significance and Environmental Impact, Geophys. Monogr., Vol. 134, Amer. Geophys. Union, 1-35.

Kalnay, E., and Coauthors, 1996: The NCEP/NCAR 40-Year Reanalysis Project. Bull. Amer. Meteor. Soc., 77, 437-471, https://doi.org/10.1175/1520-0477(1996)077<0437:TNYRP> 2.0.CO;2.

Kanamitsu, M., W. Ebisuzaki, J. Woollen, S.-K. Yang, J. J. Hnilo, M. Fiorino, and G. L. Potter, 2002: NCEP-DOE AMIP-II Reanalysis (R-2). Bull. Amer. Meteor. Soc., 83, 1631-1644, https://doi.org/10.1175/BAMS-83-11-1631.

Kerr, R. A., 2000: A North Atlantic climate pacemaker for the centuries. Science, 288, 1984-1986, https://doi.org/10.1126/ science.288.5473.1984.

Li, J., C. Sun, and F.-F. Jin, 2013: NAO implicated as a predictor of Northern Hemisphere mean temperature multidecadal variability. Geophys. Res. Lett., 40, 5497-5502, https://doi.org/ 10.1002/2013GL057877.

Li, Y., and N.-C. Lau, 2012a: Contributions of downstream eddy development to the teleconnection between ENSO and the atmospheric circulation over the North Atlantic. J. Climate, 25, 4993-5010, https://doi.org/10.1175/JCLI-D-11-00377.1.

$\longrightarrow$, and — 2012b: Impact of ENSO on the atmospheric variability over the North Atlantic in late winter-Role of transient eddies. J. Climate, 25, 320-342, https://doi.org/10.1175/ JCLI-D-11-00037.1.

Lübbecke, J. F., B. Rodríguez-Fonseca, I. Richter, M. Martín-Rey, T. Losada, I. Polo, and N. Keenlyside, 2018: Equatorial Atlantic variability-Modes, mechanisms, and global teleconnections. Wiley Interdiscip. Rev.: Climate Change, 9, e527, https://doi.org/10.1002/WCC.527.

Marshall, J., H. Johnson, and J. Goodman, 2001: A study of the interaction of the North Atlantic Oscillation with ocean circulation. J. Climate, 14, 1399-1421, https://doi.org/10.1175/ 1520-0442(2001)014<1399:ASOTIO>2.0.CO;2.

Martin, T., A. Reintges, and M. Latif, 2019: Coupled North Atlantic subdecadal variability in CMIP5 models. J. Geophys. Res. Oceans, 124, 2404-2417, https://doi.org/10.1029/2018JC014539.

McCarthy, G. D., I. D. Haigh, J. J.-M. Hirschi, J. P. Grist, and D. A. Smeed, 2015: Ocean impact on decadal Atlantic climate variability revealed by sea-level observations. Nature, 521, 508510, https://doi.org/10.1038/nature14491.

_ , T. M. Joyce, and S. A. Josey, 2018: Gulf Stream variability in the context of quasi-decadal and multidecadal Atlantic climate variability. Geophys. Res. Lett., 45, $11257-11264$, https:// doi.org/10.1029/2018GL079336.

Monerie, P., J. Robson, B. Dong, D. L. R. Hodson, and N. P. Klingaman, 2019: Effect of the Atlantic multidecadal variability on the global monsoon. Geophys. Res. Lett., 46, 17651775, https://doi.org/10.1029/2018GL080903.

Namias, J., and R. M. Born, 1970: Temporal coherence in North Pacific sea-surface temperature patterns. J. Geophys. Res., 75, 5952-5955, https://doi.org/10.1029/JC075i030p05952.

Nigam, S., A. Ruiz-Barradas, and L. Chafik, 2018: Gulf Stream excursions and sectional detachments generate the decadal pulses in the Atlantic multidecadal oscillation. J. Climate, 31, 2853-2870, https://doi.org/10.1175/JCLI-D-17-0010.1.

O'Reilly, C. H., L. M. Huber, T. Woollings, and L. Zanna, 2016: The signature of low-frequency oceanic forcing in the Atlantic
Multidecadal Oscillation. Geophys. Res. Lett., 43, 2810-2818, https://doi.org/10.1002/2016GL067925.

Penland, C., and L. M. Hartten, 2014: Stochastic forcing of north tropical Atlantic sea surface temperatures by the North Atlantic Oscillation. Geophys. Res. Lett., 41, 2126-2132, https://doi.org/ 10.1002/2014GL059252.

Portis, D. H., J. E. Walsh, M. El Hamly, and P. J. Lamb, 2001: Seasonality of the North Atlantic Oscillation. J. Climate, 14, 2069-2078, https://doi.org/10.1175/1520-0442(2001)014<2069: SOTNAO $>2.0 . \mathrm{CO} ; 2$.

Reintges, A., M. Latif, and W. Park, 2017: Sub-decadal North Atlantic Oscillation variability in observations and the Kiel Climate Model. Climate Dyn., 48, 3475-3487, https://doi.org/ 10.1007/s00382-016-3279-0.

Schlesinger, M. E., 1994: An oscillation in the global climate system of period 65-70 years. Nature, 367, 723-726, https://doi.org/ 10.1038/367723a0.

Seager, R., Y. Kushnir, M. Visbeck, N. Naik, J. Miller, G. Krahmann, and H. Cullen, 2000: Causes of Atlantic Ocean climate variability between 1958 and 1998. J. Climate, 13, 2845-2862, https://doi.org/ 10.1175/1520-0442(2000)013<2845:COAOCV > 2.0.CO;2.

Srivastava, A., and T. DelSole, 2017: Decadal predictability without ocean dynamics. Proc. Natl. Acad. Sci. USA, 114, 21772182, https://doi.org/10.1073/pnas.1614085114.

Sun, C., J. Li, and F.-F. Jin, 2015: A delayed oscillator model for the quasi-periodic multidecadal variability of the NAO. Climate Dyn., 45, 2083-2099, https://doi.org/10.1007/s00382-0142459-z.

Sutton, R. T., and D. L. R. Hodson, 2005: Atlantic Ocean forcing of North American and European summer climate. Science, 309, 115-118, https://doi.org/10.1126/science.1109496.

Timlin, M. S., M. A. Alexander, and C. Deser, 2002: On the reemergence of North Atlantic SST anomalies. J. Climate, 15, 2707-2712, https://doi.org/10.1175/1520-0442(2002)015<2707: OTRONA $>2.0 . \mathrm{CO} ; 2$.

Ting, M., Y. Kushnir, R. Seager, and C. Li, 2009: Forced and internal twentieth-century SST trends in the North Atlantic. J. Climate, 22, 1469-1481, https://doi.org/10.1175/2008JCLI 2561.1.

,-- , and -2011 : Robust features of Atlantic multidecadal variability and its climate impacts. Geophys. Res. Lett., 38, L17705, https://doi.org/10.1029/2011GL048712.

Trenberth, K., and D. J. Shea, 2006: Atlantic hurricanes and natural variability in 2005. Geophys. Res. Lett., 33, L12704, https:// doi.org/10.1029/2006GL026894.

Visbeck, M., E. P. Chassignet, R. G. Curry, T. L. Delworth, R. R. Dickson, and G. Krahmann, 2003: The ocean's response to North Atlantic Oscillation variability. The North Atlantic Oscillation: Climate Significance and Environmental Impact, Geophys. Monogr., Vol. 134, Amer. Geophys. Union, 113-145.

Wang, C., and L. Zhang, 2013: Multidecadal ocean temperature and salinity variability in the tropical North Atlantic: Linking with the AMO, AMOC, and subtropical cell. J. Climate, 26, 6137-6162, https://doi.org/10.1175/JCLI-D-12-00721.1.

Wu, Z., and N. E. Huang, 2009: Ensemble empirical mode decomposition: A noise-assisted data analysis method. Adv. Adapt. Data Anal., 01, 1-41, https://doi.org/10.1142/S1793536909000047.

Yu, L., and R. A. Weller, 2007: Objectively analyzed air-sea heat fluxes for the global ice-free oceans (1981-2005). Bull. Amer. Meteor. Soc., 88, 527-540, https://doi.org/10.1175/BAMS-88-4527.

Yuan, T., L. Oreopoulos, M. Zelinka, H. Yu, J. R. Norris, M. Chin, S. Platnick, and K. Meyer, 2016: Positive low cloud and dust 
feedbacks amplify tropical North Atlantic Multidecadal Oscillation. Geophys. Res. Lett., 43, 1349-1356, https:// doi.org/10.1002/2016GL067679.

Zhang, L., and C. Wang, 2013: Multidecadal North Atlantic sea surface temperature and Atlantic meridional overturning circulation variability in CMIP5 historical simulations. J. Geophys. Res. Oceans, 118, 5772-5791, https://doi.org/ 10.1002/jgrc. 20390.

Zhang, R., and T. L. Delworth, 2006: Impact of Atlantic Multidecadal Oscillations on India/Sahel rainfall and Atlantic hurricanes. Geophys. Res. Lett., 33, L17712, https://oi.org/ 10.1029/2006GL026267.

—_, and —_, 2007: Impact of the Atlantic Multidecadal Oscillation on North Pacific climate variability. Geophys. Res. Lett., 34, L23708, https://doi.org/10.1029/2007GL031601.

, R. Sutton, G. Danabasoglu, T. L. Delworth, W. M. Kim, J. Robson, and S. G. Yeager, 2016: Comment on "The Atlantic Multidecadal Oscillation without a role for ocean circulation." Science, 352, 1527, https://doi.org/10.1126/ science.aaf1660. 